NBER WORKING PAPER SERIES

\title{
DEMOGRAPHICS, WEALTH, AND GLOBAL IMBALANCES \\ IN THE TWENTY-FIRST CENTURY
}

\author{
Adrien Auclert \\ Hannes Malmberg \\ Frederic Martenet \\ Matthew Rognlie \\ Working Paper 29161 \\ http://www.nber.org/papers/w29161 \\ NATIONAL BUREAU OF ECONOMIC RESEARCH \\ 1050 Massachusetts Avenue \\ Cambridge, MA 02138 \\ August 2021, Revised August 2021
}

For helpful comments, we thank Rishabh Aggarwal, Mark Aguiar, Anmol Bhandari, Olivier Blanchard, Maricristina De Nardi, Charles Goodhart, Nezih Guner, Fatih Guvenen, Daniel Harenberg, Martin Holm, Gregor Jarosch, Patrick Kehoe, Patrick Kiernan, Pete Klenow, Dirk Krueger, Kieran Larkin, Ellen McGrattan, Kurt Mitman, Ben Moll, Serdar Ozkan, Christina Patterson, Alessandra Peter, Jim Poterba, Jacob Robbins, Richard Rogerson, Ananth Seshadri, Isaac Sorkin, Kjetil Storesletten, Ludwig Straub, Amir Sufi, Chris Tonetti, David Weil, Arlene Wong, Owen Zidar and Nathan Zorzi. We also thank Etienne Gagnon and John Sabelhaus for sharing code and data. This research is supported by the Hellman Faculty Scholar Fund Grant at Stanford and the Heller-Hurwicz Institute at the University of Minnesota. The views expressed herein are those of the authors and do not necessarily reflect the views of the National Bureau of Economic Research.

NBER working papers are circulated for discussion and comment purposes. They have not been peer-reviewed or been subject to the review by the NBER Board of Directors that accompanies official NBER publications.

(C) 2021 by Adrien Auclert, Hannes Malmberg, Frederic Martenet, and Matthew Rognlie. All rights reserved. Short sections of text, not to exceed two paragraphs, may be quoted without explicit permission provided that full credit, including $\odot$ notice, is given to the source. 
Demographics, Wealth, and Global Imbalances in the Twenty-First Century

Adrien Auclert, Hannes Malmberg, Frederic Martenet, and Matthew Rognlie

NBER Working Paper No. 29161

August 2021, Revised August 2021

JEL No. E21,F21,J11

\begin{abstract}
We use a sufficient statistic approach to quantify the general equilibrium effects of population aging on wealth accumulation, expected asset returns, and global imbalances. Combining population forecasts with household survey data from 25 countries, we measure the compositional effect of aging: how a changing age distribution affects wealth-to-GDP, holding the age profiles of assets and labor income fixed. In a baseline overlapping generations model this statistic, in conjunction with cross-sectional information and two standard macro parameters, pins down general equilibrium outcomes. Since the compositional effect is positive, large, and heterogeneous across countries, our model predicts that population aging will increase wealth-toGDP ratios, lower asset returns, and widen global imbalances through the twenty-first century. These conclusions extend to a richer model in which bequests, individual savings, and the taxand-transfer system all respond to demographic change.
\end{abstract}

Adrien Auclert

Department of Economics

Stanford University

579 Jane Stanford Way

Stanford, CA 94305

and NBER

aauclert@stanford.edu

Hannes Malmberg

University of Minnesota

pmalmber@umn.edu
Frederic Martenet

Department of Economics

Stanford University

579 Jane Stanford Way

Stanford, CA 94305

martenet@stanford.edu

Matthew Rognlie

Department of Economics

Northwestern University

2211 Campus Drive

Evanston, IL 60208

and NBER

matthew.rognlie@northwestern.edu

A appendix is available at http://www.nber.org/data-appendix/w29161 


\section{Introduction}

The world is experiencing rapid demographic change. The average share of the population above 50 years of age has increased from $15 \%$ to $25 \%$ since the 1950 s, and it is expected to rise further to $40 \%$ by the end of the twenty-first century (Figure 1, Panel A). There is a widespread view that this aging process has been an important driver of three key macroeconomic trends to date. According to this view, an aging population saves more, helping to explain why wealth-to-GDP ratios have risen and average rates of return have fallen (Figure 1, Panels B and C). ${ }^{1}$ Insofar as this mechanism is heterogeneous across countries, it can further explain the rise of global imbalances (Figure 1, Panel D).

Beyond this qualitative consensus lies substantial disagreement about magnitudes. For instance, structural estimates of the effect of demographics on interest rates over the 1970-2015 period range from a moderate decline of less than 100 basis points (Gagnon, Johannsen and López-Salido 2021) to a large decline of over 300 basis points (Eggertsson, Mehrotra and Robbins 2019). ${ }^{2}$ Turning to predictions for the future, economists are starkly divided about the direction of the effect. Some structural models predict falling interest rates going forward (e.g. Gagnon et al. 2021, Papetti 2019). At the same time, an influential hypothesis argues, based on the dissaving of the elderly, that aging will eventually push savings rates down and interest rates back up. This argument, popular in the 1990s as the "asset market meltdown" hypothesis (Poterba 2001, Abel 2001), was recently revived under the name "great demographic reversal" (Goodhart and Pradhan 2020). In the words of ECB chief economist Philip Lane (Lane 2020):

The current phase of population ageing is contributing to the trend decline in the underlying equilibrium real interest rate [...] While a large population cohort that is saving for retirement puts upward pressure on the total savings rate, a large elderly cohort may push down aggregate savings by running down accumulated wealth.

Our paper refutes this argument and shows that, instead, demographics will continue to push strongly in the same direction, leading to falling rates of return and rising wealthto-GDP ratios. The key to our results is the compositional effect of an aging population: the direct impact of the changing age distribution on wealth-to-GDP, holding the age profiles

\footnotetext{
${ }^{1}$ We focus primarily on the expected return on total wealth, which we proxy historically by calculating the average return on total wealth, excluding changes in asset valuations. We will often refer to this measure as the "interest rate"; it has been declining since the 1950s. As is well known, safe rates of return have also fallen, though their fall is most pronounced since the 1980s. Appendix A provides more details.

${ }^{2}$ Appendix F presents a selective summary of findings in the literature and shows how to interpret them through the lens of this paper's framework.
} 
A. Share of $50+$ year-olds

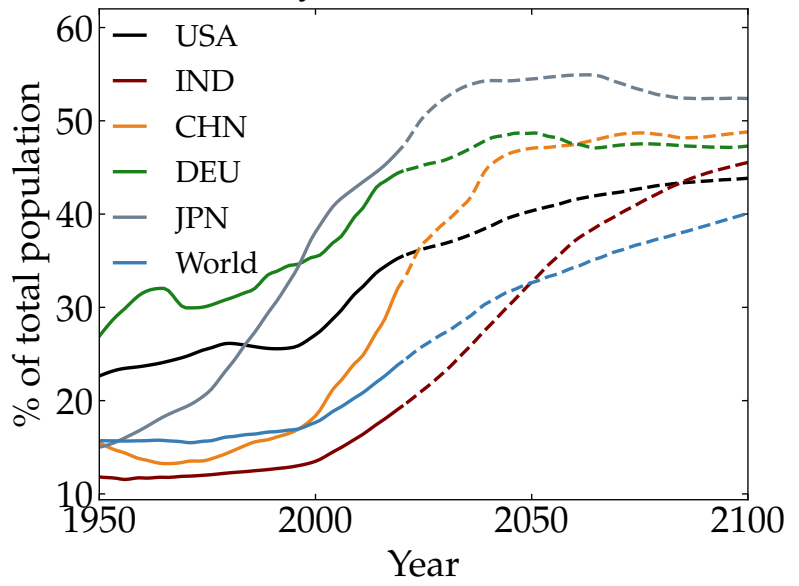

C. Ex-ante real returns

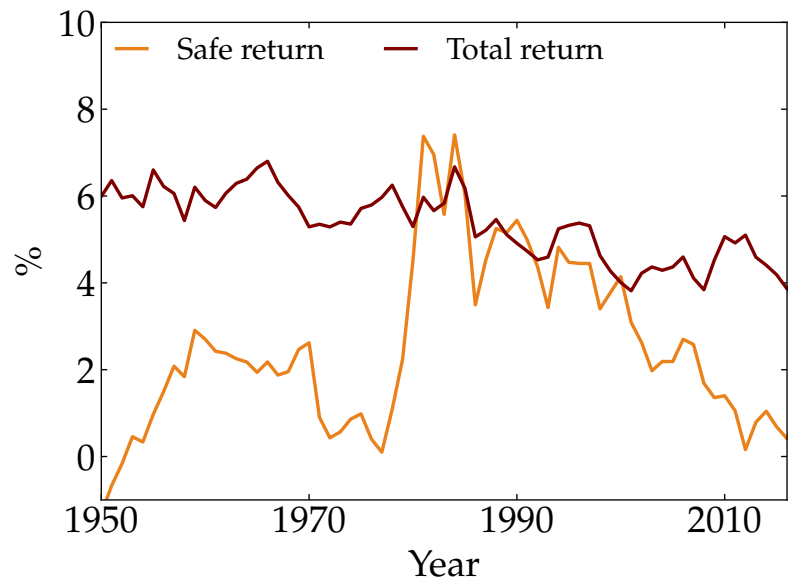

B. Private wealth-to-GDP ratios

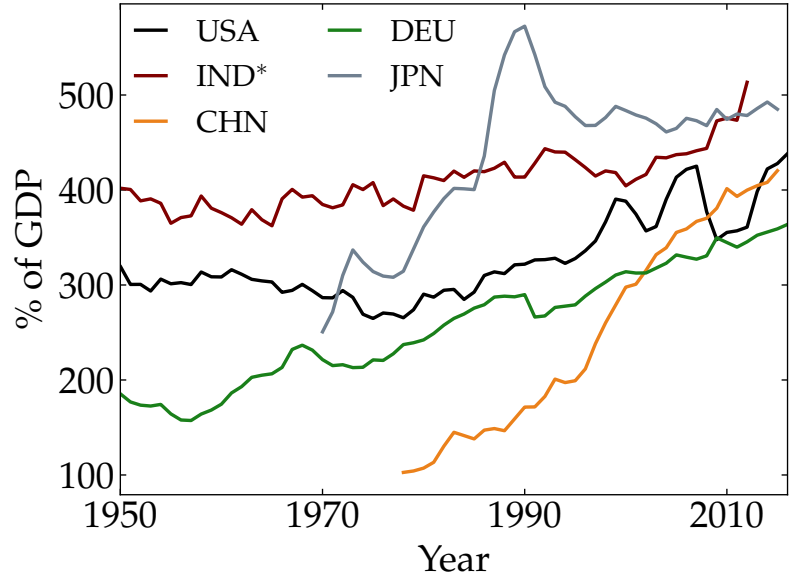

D. Net international investment positions

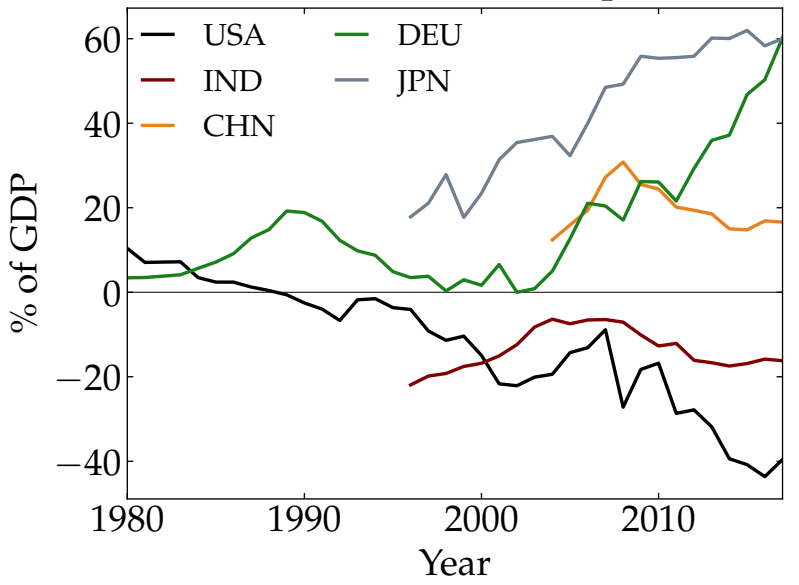

Figure 1: Demographics, wealth, interest rates and global imbalances

Notes: Panel A presents the share of 50+ year-olds in the five largest economies by GDP and the world as a whole (source: 2019 UN World Population Prospects, the projection is the central scenario). Panel B presents private wealth-to-GDP ratios (source: World Inequality Database; *: national wealth-to-GDP ratio in India). Panel C presents a measure of the US total return on wealth (orange line) and of the US safe rate of return (red line). Details on the construction of these series are in appendix A. Panel D presents net international investment positions normalized by GDP (source: IMF).

of assets and labor income fixed. In a baseline overlapping generations (OLG) model, this is a sufficient statistic for the actual change in wealth-to-GDP for a small open economy. Further, for a world economy, the compositional effect-when aggregated across countries, and combined with elasticities of asset supply and demand that we obtain with other sufficient statistic formulas-fully pins down the general equilibrium effect on wealth-to-GDP, asset returns, and global imbalances.

We measure the compositional effect by combining population forecasts with household survey data from 25 countries over the period 2016-2100. We find that it is positive 
and large everywhere, but also heterogeneous, ranging from an increase in wealth-toGDP of 48pp in Hungary to 327pp in India. Since the average effect is positive and large, our model shows that there will be no great demographic reversal: through the twentyfirst century, population aging will continue to push down global rates of return, with our central estimate being -123bp, and push up global wealth-to-GDP, with our central estimate being a $10 \%$ increase, or $47 \mathrm{pp}$ in levels. Since the effect is heterogeneous across countries, our model predicts that demographics will also generate large global imbalances. For instance, we find that India's net foreign asset position will steadily grow until it reaches $100 \%$ of GDP in 2100, while the United States's net foreign asset position will decline to absorb this demand for assets.

Our sufficient statistic framework offers a transparent way to compute the effect of a changing age distribution on key macroeconomic variables. General equilibrium outcomes can be obtained with a limited amount of information: in addition to the data needed for the compositional effect, we only need data on macroeconomic aggregates and assumptions on two standard macro parameters, the elasticity of intertemporal substitution and the elasticity of substitution between capital and labor. Our framework also clarifies a key limitation of the great demographic reversal hypothesis, which focuses on the decline in one flow (savings) when another (investment) is also declining due to demographic change. In contrast, the compositional effect on stocks (rising wealth-to-GDP) unambiguously implies a falling rate of return.

Our baseline model allows for a broad range of savings motives, but rules out some mechanisms through which population aging can affect behavior. To evaluate how much these can matter, we numerically simulate a richer model in which bequests, individual savings, and the tax-and-transfer system all respond to demographic change. We find that the results are always the same qualitatively, and that with one exception-extreme fiscal adjustments that fall entirely either on tax increases or benefit cuts-they are also close quantitatively to those we obtain directly from our sufficient statistic methodology.

Existing literature has followed two broad approaches, which our paper combines, to quantify the impact of demographic change on macroeconomic outcomes. The first is reduced-form. One branch of this literature, following Mankiw and Weil (1989) and Poterba (2001), computes the effect of a changing age distribution over fixed asset profiles. ${ }^{3}$ Another branch, following Cutler, Poterba, Sheiner, Summers and Akerlof (1990) and the "demographic dividend" literature (Bloom, Canning and Sevilla 2003), computes

\footnotetext{
${ }^{3}$ There is also a tradition that computes the effect of changing age distributions over fixed age profiles of savings rates (Summers and Carroll 1987, Auerbach and Kotlikoff 1990, Bosworth, Burtless and Sabelhaus 1991). This calculation is subject to measurement error and may not give the correct sign of the effect on rates of return, as we show in section 5 .
} 
the effect of changing age distributions over fixed income profiles. These "shift-share" calculations are very intuitive, but are not tied to specific general equilibrium counterfactuals. We show that a particular ratio of two such shift-shares is the main determinant of equilibrium outcomes in a fully specified OLG model.

The alternative approach is structural, relying on quantitative general equilibrium OLG models. This tradition, which originated in Auerbach and Kotlikoff (1987), has tackled effects of demographics on aggregate wealth accumulation, ${ }^{4}$ asset returns, ${ }^{5}$ and international capital flows. ${ }^{6}$ Our contribution here is to trace quantitative results back to primitive elasticities, and to the calibration moments that are relevant for the counterfactual of interest. One benefit of this approach is that it can identify the source of conflicting estimates: for instance, the compositional effect in Gagnon et al. (2021) is about the same as in the data, while that in Eggertsson et al. (2019) is about triple that in the data.

In this paper, we focus on the causal effect of projected demographic change in the twenty-first century. We do not explain the underlying sources of this change; instead, we take demographic projections as given. We also rule out some indirect effects of aging, such as changes in total factor productivity or market structure, which are difficult for us to quantify. ${ }^{7}$ Although our baseline exercise holds government debt-to-GDP policy fixed, we show how rising government debt can mitigate or even undo the effect of demographic change on real interest rates, while increasing the effect on wealth-to-GDP. ${ }^{8}$

The compositional effects we identify are large, both in the past and in the future. This suggests that demographic change is an important force behind macroeconomic trends. Of course, other developments have also played a major role historically, and our focus on the causal effect of demographic change should not be interpreted as ruling them out. ${ }^{9}$

The paper proceeds as follows. In section 2, we describe our baseline model and define the compositional effect. We show that the effect of aging on wealth-to-GDP in a small

\footnotetext{
${ }^{4}$ e.g. İmrohoroğlu, İmrohoroğlu and Joines (1995), Kotlikoff, Smetters and Walliser (1999), De Nardi, Imrohoroğlu and Sargent (2001), and Kitao (2014).

${ }^{5}$ e.g. Abel (2003), Geanakoplos, Magill and Quinzii (2004), Carvalho, Ferrero and Nechio (2016), Eggertsson et al. (2019), Lisack, Sajedi and Thwaites (2017), Jones (2020), Papetti (2019), Rachel and Summers (2019), Kopecky and Taylor (2020), and Gagnon et al. (2021).

${ }^{6}$ e.g. Henriksen (2002), Börsch-Supan, Ludwig and Winter (2006), Domeij and Flodén (2006), Krueger and Ludwig (2007), Backus, Cooley and Henriksen (2014), and Bárány, Coeurdacier and Guibaud (2019).

${ }^{7}$ For the effects of population aging on TFP, see the debate between Maestas, Mullen and Powell (2016) and Acemoglu and Restrepo (2017). For models in which demographics can affect markups via either the structure of consumer demand or firm entry incentives, see Bornstein (2020) vs. Peters and Walsh (2019).

${ }^{8}$ Our quantitative model also shows that increasing the retirement age increases interest rates and reduces wealth-to-GDP, though the magnitude is likely to be modest in practice.

${ }^{9}$ These forces include falling TFP growth, rising inequality, changing risk or liquidity premia, and rising markups. See, for instance, Rachel and Smith (2015), Eggertsson et al. (2019), Auclert and Rognlie (2018), Straub (2019), Farhi and Gourio (2018), and Eggertsson, Robbins and Wold (2018).
} 
open economy exactly coincides with the compositional effect, and that world equilibrium outcomes can be obtained by combining this effect with elasticities of asset supply and demand for which we also derive sufficient statistic formulas. In section 3, we turn to measurement, documenting large and heterogeneous compositional effects across 25 countries for 2016-2100, and calculating their general equilibrium implications. In section 4, we extend the baseline model to capture additional macroeconomic effects of population aging and show that the results from section 3 are a close fit in nearly all cases. Finally, in section 5 we explain why the great demographic reversal hypothesis's focus on savings rates is incomplete: although demographic forces will indeed push down net savings rates, this will be overwhelmed by an even larger decline in net investment, leading to a decrease in equilibrium rates of return.

\section{The compositional effect of demographics}

In this section, we set up a benchmark life-cycle model with overlapping generations to study the effects of demographic change. We derive two main theoretical results. First, in a small open economy, demographic change only affects macroeconomic aggregates by changing the age composition of the population. Given a demographic projection, these compositional effects can be calculated using data from a single cross-section. Second, in an integrated world economy, the long-run effects of demographic change on wealth accumulation, interest rates, and global imbalances can be obtained by simply combining these compositional effects with macroeconomic aggregates, other cross-sectional statistics, and assumptions about two primitive elasticities.

\subsection{Environment}

Our environment is a world economy with overlapping generations (OLG) of heterogeneous individuals. Time is discrete and runs from $t=0$ to $\infty$, agents have perfect foresight, and capital markets are integrated. Apart from the global return on assets, all variables and parameters are allowed to vary across countries. Country indices are dropped unless there is a risk of ambiguity.

Individuals. At each time $t$, a country has a population $N_{t}=\sum_{j} N_{j t}$ growing at rate $1+n_{t} \equiv N_{t} / N_{t-1}$, with $N_{j t}$ being the number of individuals of age $j$. Each individual faces an exogenous probability $\phi_{j}$ of surviving from age $j$ to age $j+1$, so the probability of surviving from birth to age $j$ is $\Phi_{j} \equiv \prod_{k=0}^{j-1} \phi_{k}$. The maximal lifespan is $J$, so that $\phi_{J}=0$. 
For now, we assume that this survival profile is constant over time, and that there is no migration. Hence, the age distribution, $\pi_{j t} \equiv \frac{N_{j t}}{N_{t}}$, only varies over time due to changes in fertility and convergence dynamics. ${ }^{10}$

Individuals supply labor exogenously, face idiosyncratic income risk, and can partially self-insure and smooth income over their life cycle by saving in an annuity. Their effective labor supply is $\ell\left(z_{j}\right)$, where $z_{j}$ is a stochastic process. Unless stated otherwise, all individual variables at age $j$ are a function of the whole history of the idiosyncratic shocks $z_{j}$, which we denote $z^{j}$.

Individuals with birth year $k$ choose sequences of consumption $c_{j t}$ and annuities $\mathfrak{a}_{j+1, t+1}$ for all ages $j=0, \ldots, J$ (with $t=j+k$ ) to solve the utility maximization problem

$$
\begin{aligned}
\max _{\left\{c_{j t}, \mathfrak{a}_{j+1, t+1}\right\}} & \mathbb{E}_{k}\left[\sum_{j=0}^{J} \beta_{j} \Phi_{j} \frac{{ }^{1-\frac{1}{\sigma}}}{1-\frac{1}{\sigma}}\right] \\
\text { s.t. } \quad c_{j t}+\phi_{j} \mathfrak{a}_{j+1, t+1} & \leq w_{t}\left((1-\tau) \ell\left(z_{j}\right)+\operatorname{tr}\left(z^{j}\right)\right)+\left(1+r_{t}\right) \mathfrak{a}_{j t} \\
\mathfrak{a}_{j+1, t+1} & \geq-\bar{a} Z_{t},
\end{aligned}
$$

where $\bar{a}$ is a borrowing constraint, $w_{t}$ is the real wage per efficiency unit of labor at time $t$, $r_{t}$ is the return on wealth, $\tau$ is the labor tax rate, and $\operatorname{tr}\left(z^{j}\right)$ denotes transfers from the government, including wage-indexed social insurance and retirement transfers, for agents of age $j$ with a history $z^{j}$. The utility weight at age $j$ is $\beta_{j} \Phi_{j}$, combining the survival probability $\Phi_{j}$ and an arbitrary age-specific utility shifter $\beta_{j}$. Deviations from exponential discounting $\left(\beta_{j}=\beta^{j}\right.$ for some $\beta$ ) stand in for age-dependent factors that affect the marginal utility of consumption, such as health status or the presence of children. Hence, this model can capture many of the factors that the literature considers essential to understand savings: agents save for life-cycle reasons, for self-insurance reasons, to cover future health costs, and to provide for their children. ${ }^{11}$

The total wealth held by individuals of age $j$ is the product of $N_{j t}$ and the average wealth at age $j, a_{j t} \equiv \mathbb{E} \mathfrak{a}_{j t}$. Aggregate (private) wealth $W_{t}$ is the sum across age groups:

\footnotetext{
${ }^{10}$ Convergence dynamics for demographics are sometimes called "momentum". Appendix B.1 shows that that fertility and momentum together account for the majority of population aging during the US demographic transition between 1950 and 2100. Changing mortality and migration contribute to a more limited extent, though their importance rises during the latter part of the transition.

${ }^{11}$ We assume that children live with one of their parents, whose consumption $c_{j}$ at age $j$ includes that of the children they care for. Formally, we set $\beta_{j}=\ell\left(z_{j}\right)=\operatorname{tr}\left(z_{j}\right)=0$ when $j \leq J^{w}$, for a $J^{w}$ that denotes the start of working life independent from parents. Given this assumption, children do not consume or accumulate assets until age $J^{w}$.
} 


$$
W_{t} \equiv \sum_{j=0}^{J} N_{j t} a_{j t} .
$$

Production. There is a single good used for private consumption, government consumption, and investment. The final output $Y_{t}$ of this good is produced competitively from physical capital $K_{t}$ and effective labor input $L_{t}$ according to an aggregate production function $F$

$$
Y_{t}=F\left(K_{t}, Z_{t} L_{t}\right),
$$

where $Z_{t} \equiv Z_{0}(1+\gamma)^{t}$ captures labor-augmenting technological progress. We assume that $F$ has constant returns to scale and diminishing returns to each factor. Effective labor input $L_{t}$ is a standard linear aggregator

$$
L_{t}=\sum_{j=0}^{J} N_{j t} \mathbb{E} \ell_{j},
$$

where $\mathbb{E} \ell_{j}$ denotes average effective labor input per person of age $j$, capturing variation in experience and hours of work over the life cycle. Capital has a law of motion $K_{t+1}=$ $(1-\delta) K_{t}+I_{t}$ where $I_{t}$ is aggregate investment, and factor prices equal marginal products. The net rental rate of capital is $r_{t}=F_{K}\left(K_{t} /\left(Z_{t} L_{t}\right), 1\right)-\delta$, and the wage per efficiency unit of labor is $w_{t}=Z_{t} F_{L}\left(K_{t} /\left(Z_{t} L_{t}\right), 1\right)$.

We write $g_{t} \equiv Y_{t} / Y_{t-1}-1$ for the growth rate of the economy. With a constant $r_{t}$ and a stationary population, $g_{t}=(1+\gamma)(1+n)-1$. Otherwise, $g_{t}$ also reflects changes in capital intensity and the composition of the population.

Government. The government purchases $G_{t}$ goods, maintains a constant tax rate on labor income $\tau$, gives individuals state-contingent transfers $\operatorname{tr}\left(z^{j}\right)$ indexed to current wages $w_{t}$, and finances itself using a risk-free bond with real interest rate $r_{t}$. It faces the flow budget constraint

$$
G_{t}+w_{t} \sum_{j=0}^{J} N_{j t} \mathbb{E} t r_{j}+\left(1+r_{t}\right) B_{t}=\tau w_{t} \sum_{j=0}^{J} N_{j t} \mathbb{E} \ell_{j}+B_{t+1}
$$

where a positive $B_{t}$ denotes government borrowing. When demographic change disturbs the balance of aggregate tax receipts and expenditures, the government adjusts $G_{t}$ to ensure that the debt-to-output ratio $\frac{B_{t}}{Y_{t}}$ follows a given, exogenous, time path. 
Equilibrium. Given demographics, government policy, an initial distribution of assets, and initial levels of bonds and capital across countries such that $F_{K}-\delta$ is equal to $r_{0}$ in each country, an equilibrium is a sequence of returns $\left\{r_{t}\right\}$ and country-level allocations such that, in each country, individuals optimize, firms optimize, and asset demand from individuals equals asset supply from firms and governments,

$$
\sum_{c} W_{t}^{c}=\sum_{c}\left(K_{t}^{c}+B_{t}^{c}\right)
$$

Dividing by world GDP $Y_{t}$, the above expression can be written as

$$
\sum_{c} \frac{Y_{t}^{c}}{Y_{t}} \frac{W_{t}^{c}}{Y_{t}^{c}}=\sum_{c} \frac{Y_{t}^{c}}{Y_{t}}\left[\frac{K_{t}^{c}}{Y_{t}^{c}}+\frac{B_{t}^{c}}{Y_{t}^{c}}\right]
$$

Defining a country's net foreign asset position as the excess of wealth over capital and bonds, $N F A_{t}^{c} \equiv W_{t}^{c}-\left(K_{t}^{c}+B_{t}^{c}\right)$, (5) states that the average NFA-to-GDP ratio is zero, when countries are weighted by their by GDP.

\subsection{A small economy aging alone}

We first study a small open economy undergoing demographic change, while all other countries have constant demographic parameters. In this case, the economy faces a global rate of return $r$ which is exogenous and fixed-exogenous because the economy is small, and fixed since all other countries have fixed demography. This can be seen as the limit case when the economy has an arbitrarily small world GDP weight $\frac{Y_{t}^{c}}{Y_{t}}$, so that its demand and supply of assets do not affect the world equilibrium condition (5). ${ }^{12}$ By studying this case, we can analyze how demographics affect macroeconomic aggregates directly, independent of any effects operating through equilibrium adjustments in returns $r_{t}$.

We focus on wealth, and our key finding is that demographic change does not affect the wealth levels within age groups, only the distribution of the population across age groups. Formally, the economy exhibits what we call balanced growth by age, where the full distribution of wealth within every age group grows at a constant rate.

Lemma 1. For any fixed $r$, a small open economy eventually reaches a balanced growth path by age on which, for each age $j$, the full distribution of wealth holdings grows at the same rate $\gamma$ as

\footnotetext{
${ }^{12}$ To obtain a fixed interest rate, we assume that all other countries $c^{\prime} \neq c$ are in demographic steady state given a set of mortality profiles $\phi_{j}^{c}$ and a common growth rate of newborns $n$, where the constant growth rate ensures that countries preserve their relative size over time.
} 
technology. In particular, average wealth at age $j$ satisfies

$$
\frac{a_{j t}}{Z_{t}}=a_{j}(r)
$$

for sufficiently large $t$ and some function $a_{j}(r)$. If initial asset holdings reflect optimal choices given the fixed $r$ (in which case $a_{j 0} / Z_{0}=a_{j}(r)$ ), the economy starts on this balanced growth path, and equation (6) holds for all $t$ and $j$.

Proof. See appendix B.2.

The lemma follows since demographic change does not affect the parameters of individuals' life-cycle problems, once these problems are normalized by productivity. Hence, individuals born at different times make the same normalized asset choices given their age, state, and asset holdings. As the influence of initial asset holdings recedes, we reach a balanced growth path by age. Further, if initial assets are consistent with optimization given $r$, we start on this balanced growth path. In that case, which we assume from now on, we have $a_{j t}=(1+\gamma)^{t} a_{j 0}$ for all $t$.

Given lemma 1, aggregate wealth per person satisfies

$$
\frac{W_{t}}{N_{t}}=\sum_{j} \pi_{j t} a_{j t}=(1+\gamma)^{t} \sum_{j} \pi_{j t} a_{j 0}
$$

Wealth per person changes with the age composition $\pi_{j t}$ of the population, and otherwise grows at the technological growth rate $1+\gamma$.

We next derive output per person. A constant global $r$ implies a constant ratio of capital to effective labor $k(r)$, defined by $F_{K}(k(r), 1)=r+\delta$. Aggregate output is then $Y_{t}=Z_{t} L_{t} F(k(r), 1)$, where, from (3), aggregate effective labor is $L_{t}=N_{t} \sum_{j} \pi_{j t} \mathbb{E} \ell_{j}$. Hence

$$
\begin{aligned}
\frac{Y_{t}}{N_{t}} & =Z_{t} F(k(r), 1) \sum_{j} \pi_{j t} \mathbb{E} \ell_{j} \\
& =\frac{F(k(r), 1)}{F_{L}(k(r), 1)}(1+\gamma)^{t} \sum_{j} \pi_{j t} h_{j 0}
\end{aligned}
$$

where $h_{j 0}=Z_{0} F_{L} \mathbb{E} \ell_{j}=w_{0} \mathbb{E} \ell_{j}$ is equal to average labor earnings of individuals of age $j$, and we have used the fact that the initial wage is $w_{0}=Z_{0} F_{L}(k(r), 1)$.

Taking the ratio of (7) and (8), we find that $W_{t} / Y_{t}$ is proportional to the ratio of $\sum_{j} \pi_{j t} a_{j 0}$ and $\sum_{j} \pi_{j t} h_{j 0}$. The following proposition summarizes this result. 
Proposition 1. On the balanced growth path by age, the wealth-to-GDP ratio satisfies

$$
\frac{W_{t}}{Y_{t}} \propto \frac{\sum \pi_{j t} a_{j 0}}{\sum \pi_{j t} h_{j 0}}
$$

where $h_{j 0} \equiv \mathbb{E} w_{0} \ell_{j}$ is average pre-tax labor income by age, and $a_{j 0} \equiv \mathbb{E} a_{j t}$ is average asset holdings by age.

The proposition implies that all changes in $W_{t} / Y_{t}$ reflect the changing age composition $\pi_{j t}$ of the population, given fixed age profiles $a_{j 0}$ and $h_{j 0}$. Equation (9) implies that the log change in wealth to GDP between year 0 and year $t$ is given by

$$
\log \left(\frac{W_{t}}{Y_{t}}\right)-\log \left(\frac{W_{0}}{Y_{0}}\right)=\log \left(\frac{\sum \pi_{j t} a_{j 0}}{\sum \pi_{j t} h_{j 0}}\right)-\log \left(\frac{\sum \pi_{j 0} a_{j 0}}{\sum \pi_{j 0} h_{j 0}}\right) \equiv \Delta_{t}^{c o m p} .
$$

The key feature of equation (10) is that $\Delta_{t}^{\text {comp }}$ can be calculated from demographic projections and cross-sectional data alone, with demographic projections providing $\pi_{j t}$ and cross-sectional data providing $a_{j 0}$ and $h_{j 0}$. We call $\Delta_{t}^{\text {comp }}$ the compositional effect of aging on $W_{t} / Y_{t}$. Proposition 1 shows that, for a small open economy, this equals the log change in $W_{t} / Y_{t}$. The next section shows that $\Delta_{t}^{\text {comp }}$ also plays a key role in an integrated world economy.

\subsection{Many countries aging together}

We now study the general case where all countries age together, and $r_{t}$ adjusts to clear the global asset market. Using an asset supply and demand framework, we find that demographic change increases global asset demand by exactly the average compositional effect (10). We develop this observation into a sufficient statistic result for long-run outcomes, which can be calculated by combining compositional effects with semielasticities of asset demand and supply. These semielasticities, in turn, can be given closed-form expressions in terms of observables and standard macro parameters.

Our analysis starts from a first order approximation of the world asset market clearing condition (5). To simplify, we assume here that net foreign asset positions are zero at an initial date $t=0$, and that governments target a constant $B_{t}^{c} / Y_{t}^{c}$. We relax these assumptions in appendix B.4. We obtain:

$$
\sum_{c} \frac{Y_{0}^{c}}{Y_{0}} \Delta\left(\frac{W_{t}^{c}}{Y_{t}^{c}}\right)=\sum_{c} \frac{Y_{0}^{c}}{Y_{0}} \Delta\left(\frac{K_{t}^{c}}{Y_{t}^{c}}\right),
$$


where $\Delta$ denotes level changes between time 0 and $t$. The left of (11) is the change in global asset demand, while the right is the change in global asset supply.

We focus on changes between time 0 and the "long run" $L R$, when the world has converged to a demographic steady state. Denote by $\epsilon^{c, d} \equiv \frac{\partial \log \left(W^{c} / Y^{c}\right)}{\partial r}$ the semielasticity of country $c^{\prime}$ s aggregate asset demand to the rate of return, ${ }^{13}$ and by $\epsilon^{s, c} \equiv-\frac{\partial \log \left(\left(K^{c}+B^{c}\right) / Y^{c}\right)}{\partial r}=$ $\frac{\eta}{r_{0}+\delta} \frac{K_{0}^{c}}{W_{0}^{c}}$ its semielasticity of asset supply, where $\eta$ denotes the elasticity of substitution between capital and labor. For changes between $t=0$ and $t=L R$, equation (11) then becomes

$$
\bar{\Delta}_{L R}^{c o m p}+\bar{\epsilon}^{d} \cdot\left(r_{L R}-r_{0}\right) \simeq-\bar{\epsilon}^{s} \cdot\left(r_{L R}-r_{0}\right),
$$

where bars denote averages across countries using initial wealth shares $\omega^{c} \equiv W_{0}^{c} / W_{0}$ (see the proof of proposition 2 in appendix B.3 for a derivation).

Equation (12) shows that demographics affect equilibrium outcomes by shifting out the asset demand curve by the average compositional effect. In this sense, the compositional effect summarizes the full demographic "shock" to the world equilibrium. Aggregate outcomes are obtained by filtering this shock through the semielasticities $\bar{\epsilon}^{d}$ and $\bar{\epsilon}^{s}$. Solving (12) for $r_{L R}-r_{0}$, we obtain the following proposition.

Proposition 2. If agents start on a balanced growth path by age, initial net foreign asset positions are zero, and governments maintain debt-to-GDP ratios constant, the long-run change in the rate of return is, up to a first order approximation,

$$
r_{L R}-r_{0} \simeq-\frac{1}{\bar{\epsilon}^{d}+\bar{\epsilon}^{s}} \bar{\Delta}_{L R}^{c o m p}
$$

where $\bar{\epsilon}^{s}=\frac{\eta}{r_{0}+\delta} \bar{K}_{0}$ is the average semielasticity of asset supply to $r$, and $\bar{\epsilon}^{d}$ is the average semielasticity of individual asset holdings to $r$. The wealth-weighted average log change in the wealth-toGDP ratio is given by

$$
\overline{\Delta_{L R} \log \left(\frac{W}{Y}\right)} \simeq \frac{\bar{\epsilon}^{s}}{\bar{\epsilon}^{s}+\bar{\epsilon}^{d}} \bar{\Delta}_{L R}^{c o m p}
$$

Proof. See appendix B.3.

Intuitively, the average compositional effect $\bar{\Delta}_{L R}^{c o m p}$ creates an excess demand for assets at fixed $r$, which must be absorbed by an increase in the world capital stock and/or a reduction in asset accumulation. If $\bar{\epsilon}^{s}+\bar{\epsilon}^{d}$ is large, $r$ falls little, because capital and assets

\footnotetext{
${ }^{13}$ Formally, $\epsilon^{d, c}$ is the derivative with respect to $r$ of the balanced growth level of $\log W / Y$ in a small open economy with exogenous $r$, evaluated at the long-run steady-state age distribution. This includes both the direct individual asset accumulation response to $r$, and the indirect response from the effect of $r$ on wages. We discuss $\epsilon^{d, c}$ further in the next section.
} 
are very sensitive to $r$. If $\frac{\bar{\epsilon}^{s}}{\bar{\epsilon}^{s}+\bar{\epsilon}^{d}}$ is large, wealth rises a lot, because a large share of the adjustment occurs through increases in the capital stock rather than through a reduction in asset accumulation.

Beyond interest rates and wealth levels, our framework also speaks to global imbalances. To see why, note first that absent an adjustment in $r$, the net foreign asset position (NFA) of a country would increase one-for-one with its compositional effect. In equilibrium, $r$ must fall to ensure that NFAs are zero on average, so the adjustment in $r$ has to reduce the average NFA by the average compositional effect. Hence, the change in a country's NFA is determined by the difference between its compositional effect and the average compositional effect, subject to an additional adjustment when countries have different semielasticities to $r$. The following proposition summarizes this result.

Proposition 3. Given the conditions of proposition 2, the long-run change in country c's net foreign asset position $N F A^{c}$ satisfies

$$
\log \left(1+\frac{\Delta_{L R} N F A^{c} / Y^{c}}{W_{0}^{c} / Y_{0}^{c}}\right) \simeq \Delta_{L R}^{c o m p, c}-\bar{\Delta}_{L R}^{c o m p}+\left(\epsilon^{d, c}+\epsilon^{s, c}-\left(\bar{\epsilon}^{d}+\bar{\epsilon}^{s}\right)\right)\left(r_{L R}-r_{0}\right)
$$

Proof. See appendix B.3.

Since we have no direct way to predict the effect of demographics on long-run government debt targets, propositions 2 and 3 both assume a benchmark where each country keeps long-run debt-to-GDP constant. Appendix B.4 discusses alternative settings where debt-to-GDP changes in response to demographics. Two special cases stand out: when each country increases its debt-to-GDP target by the amount of its compositional effect, and when each country increases debt-to-GDP by the average world compositional effect. In the first case, there is no change in interest rates or net foreign assets, and each country's wealth increases by exactly its compositional effect. In the second case, the same conclusions hold for interest rates and wealth, but net foreign assets in each country increase by the difference between its compositional effect and the global average, leaving the global imbalances predicted by proposition 3 intact. ${ }^{14}$

\subsection{The asset demand semielasticity $\epsilon^{d}$}

Propositions 2 and 3 show that the compositional effects determine aggregate outcomes given the set of asset supply and demand semielasticities $\epsilon^{\mathcal{S}}$ and $\epsilon^{d}{ }^{15}$ The asset supply

\footnotetext{
${ }^{14}$ This second case can be viewed as the limit of a specification where we make long-term debt-to-GDP highly responsive to interest rates, taking $\partial\left(B^{c} / Y^{c}\right) / \partial r$ uniformly to $-\infty$ across all countries.

${ }^{15}$ In this section we drop the country superscripts $c$ for convenience. Subscripts $c$ denote consumption.
} 
semielasticity $\epsilon^{S}$ is only a function of observables and of the elasticity of substitution between labor and capital $\eta$.

The asset demand semielasticity $\epsilon^{d}$ is more challenging to obtain. As noted by Saez and Stantcheva (2018), there is a "paucity of empirical estimates" for how long-run asset accumulation responds to changes in the rate of return. ${ }^{16}$ Remarkably, however, in a version of our model without income risk and borrowing constraints, it is possible to express $\epsilon^{d}$ only in terms of macroeconomic aggregates, the observed age profiles of assets and consumption, and the elasticity of intertemporal substitution $\sigma$. The latter is a standard macro parameter that has been the topic of an extensive empirical literature.

To build intuition, we first study the case where technology is Cobb-Douglas and $r=g$ in the initial steady state. In that case, our result takes a simple form:

$$
\epsilon^{d}=\sigma \underbrace{\frac{C}{(1+g) W} \frac{\operatorname{Var} A g e_{c}}{1+r}}_{\equiv \epsilon_{\text {substitution }}^{d}}+\underbrace{\frac{\mathbb{E} A g e_{c}-\mathbb{E} A g e_{a}}{1+r}}_{\equiv \epsilon_{\text {income }}^{d}} .
$$

Here, $A g e_{a}$ and $A g e_{c}$ are random variables that capture how asset holdings and consumption are distributed across different ages. The random variables range over ages $j$, with probabilities proportional to assets and consumption at each age. ${ }^{17}$ Thus, $\operatorname{Var} A g e_{c}$ is large when consumption is spread out across different ages, and $\mathbb{E} A g e_{c}-\mathbb{E} A g e_{a}$ is large if consumption, on average, occurs at higher ages than asset holdings do.

In appendix B.5, we derive equation (16), connecting it to the broader logic of life-cycle problems and the cross-sectional outcomes that they produce. The substitution effect $\sigma \epsilon_{\text {substitution }}^{d}$ scales with the elasticity of intertemporal substitution, and is proportional to $\operatorname{Var} \mathrm{Age}_{\mathrm{c}}$ since there is more scope for intertemporal substitution if consumption is more spread out over the life cycle. The income effect $\epsilon_{i n c o m e}^{d}$ reflects the fact that a higher $r$ increases total income. The size of the increase is proportional to total wealth $W$ and accrues at an average age of $\mathbb{E} A g e_{a}$, and it is used to increase consumption by a uniform proportion across all ages, implying that the rise in consumption occurs at an average age of $\mathbb{E} A g e_{c}$. Aggregate wealth increases if $\mathbb{E} A g e_{a}$ is lower than $\mathbb{E} A g e_{c}$, because then, on average, the extra interest income is saved before it is consumed.

\footnotetext{
${ }^{16}$ An elasticity of this kind is important in a variety of contexts, including capital taxation (Feldstein 1978, Saez and Stantcheva 2018), the response of interest rates to automation (Moll, Rachel and Restrepo 2021), and the welfare implications of increasing the public debt (Aguiar, Amador and Arellano 2021). See section 3.2 for a discussion of empirical estimates.

${ }^{17}$ Formally, we define the probability mass of $A g e_{a}$ at each age $j$ to be $\pi_{j} a_{j} / A$, the share of assets in the cross-section held by people of age $j$, and likewise for $A g e_{c}$. For the case $g=0$, this is equivalent to defining the mass as the share of assets held at age $j$ across the life cycle, but with the cross-sectional definition our result holds more generally.
} 
For the more general case, there are two complications. First, when technology is not Cobb-Douglas, the labor share changes with $r$, introducing a new term. Second, our previous result relied on current values being the same as present values normalized by growth, which is no longer true when $r \neq g$. Writing $\hat{r} \equiv \frac{1+r}{1+g}-1$, we define the present value versions of aggregates: $W^{P V} \equiv \sum_{j} \frac{\pi_{j} a_{j}}{(1+\hat{r})^{j}}$ and $C^{P V} \equiv \sum_{j} \frac{\pi_{j} a_{j}}{(1+\hat{r})^{j}}$, and $A g e_{a}^{P V}$ and $A g e_{c}^{P V}$ as random variables having probability masses at $j$ proportional to $\frac{\pi_{j} a_{j}}{(1+\hat{r})^{j}}$ and $\frac{\pi_{j} c_{j}}{(1+\hat{r})^{j}}$ respectively. This leads us to the following proposition.

Proposition 4. Consider a small open economy with a steady-state population distribution $\pi$. If individuals face no income risk or borrowing constraints, the long-run semielasticity of the steadystate $W / Y$ to the rate of return is given by

$$
\epsilon^{d} \equiv \frac{\partial \log W / Y}{\partial r}=\sigma \epsilon_{\text {substitution }}^{d}+\epsilon_{\text {income }}^{d}+(\eta-1) \epsilon_{\text {laborshare }}^{d}
$$

When $\hat{r}=0, \epsilon_{\text {substitution }}^{d}$ and $\epsilon_{\text {income }}^{d}$ are given by (16). When $\hat{r} \neq 0$,

$$
\begin{aligned}
\epsilon_{\text {substitution }}^{d} & =\frac{1}{1+r} \frac{C}{(1+g) W} \frac{\mathbb{E} A g e_{c}-\mathbb{E} A g e_{c}^{P V}}{\hat{r}} \\
\epsilon_{\text {income }}^{d} & =\frac{1}{1+g} \frac{\frac{C / C^{P V}}{W / W^{P V}}-1}{\hat{r}}
\end{aligned}
$$

In both cases, $\epsilon_{\text {laborshare }}^{d}$ is given by

$$
\epsilon_{\text {laborshare }}^{d} \equiv \frac{\left(1-s_{L}\right) / s_{L}}{r+\delta}, \quad s_{L} \equiv \frac{w L}{Y} .
$$

Proof. See appendix B.5.

Proposition 4 provides, to our knowledge, the first expression for the semielasticity of aggregate asset demand in a rich quantitative model as a function of measurable sufficient statistics. Earlier work has instead relied on numerical simulations (e.g. Summers 1981, Evans 1983, Cagetti 2001, Aguiar et al. 2021). While the literature has pointed out that this elasticity can be affected by idiosyncratic income uncertainty, we show in section 4 that our formula still provides a close approximation in that context. Further, the results of proposition 4 are continuous at $\hat{r}=0$, so that for small $\hat{r},(16)$ is a good approximation to the actual $\epsilon_{\text {substitution }}^{d}$ and $\epsilon_{\text {income }}^{d}{ }^{18}$

\footnotetext{
${ }^{18} \epsilon_{\text {laborshare }}^{d}$ tends to be small enough that for $\eta$ close to 1 , its contribution is insignificant.
} 


\section{Measurement and implications}

This section uses the framework provided by propositions 1-4 to quantify the impact of demographics on macroeconomic aggregates. First, we combine demographic projections with representative household surveys to measure the compositional effect $\Delta_{t}^{\text {comp }}$ in 25 countries. Second, we use information on age profiles of consumption and wealth together with assumptions on the structural elasticities $\eta$ and $\sigma$ to calculate the semielasticities of asset supply and demand to interest rates. Finally, we combine these results to forecast interest rates, wealth levels, and global imbalances until the end of the twentyfirst century.

\subsection{The compositional effect}

Implementation. We take age distributions $\pi_{j t}$ from the historical data and future projections of the United Nations World Population Prospects. For these projections, we consider three different scenarios, corresponding to the UN's baseline projection as well as their "high fertility" and "low fertility" scenarios.

For the age profiles of labor income and wealth, we use representative household surveys. We use labor income data from the Luxembourg Income Study (LIS), which provides harmonized labor surveys for a wide range of countries; we use wealth data from a collection of wealth surveys such as the US Survey of Consumer Finances (SCF) and the European Household Finance and Consumption Survey (HFCS). Our exercise starts in 2016 and the surveys are from this year whenever possible; otherwise, we use the closest available year. See appendix table A.1 for a complete list of data sources and survey years.

For labor income, the model object $h_{j 0}$ is the 2016 average pretax labor income of individuals of age $j$. We calculate it using a comprehensive measure of labor income earned by all individuals of age $j$-including wages, salaries, bonuses, fringe benefits, and selfemployment income before social security and labor income taxes-expressed as a ratio to the number of individuals of age $j$.

For assets, the model object $a_{j 0}$ is the 2016 average individual net worth of individuals of age $j$. We measure it as total assets net of liabilities, with housing ${ }^{19}$ and defined

\footnotetext{
${ }^{19}$ The fact that households accumulate assets in part through housing does not change proposition 1, though it potentially changes the general equilibrium implications in propositions 2 and 3 . In a simple model, the demand for housing is proportional to overall consumption rather than labor, meaning that the consumption-to-output ratio would appear in the ratio of asset supply to GDP, and a shift-share for this ratio would appear together with the compositional effect in (12). This could mildly attenuate the effects on real interest rates and NFAs.
} 
contribution pension wealth included as assets, and mortgages included as liabilities. For the United States, we also add age-specific estimates of the funded component of the empirically important private defined benefit (DB) pension plans. ${ }^{20}$ We map the household wealth measure from the surveys to an individual measure by splitting wealth equally across the head of household, the spouse, and any other household members who are at least as old as the head. ${ }^{21}$

We use the demographic projections and the age profiles of asset and labor income to project the compositional effect from 1950 to 2100 for the twenty-five countries in our sample. To aid interpretation, we sometimes express $\Delta_{t}^{\text {comp }}$ in terms of predicted changes in the level of wealth-to-GDP (in percentage points), rewriting (10) as

$$
\frac{W_{t}}{Y_{t}}-\frac{W_{0}}{Y_{0}}=\frac{W_{0}}{Y_{0}}\left(e^{\Delta_{t}^{c o m p}}-1\right)
$$

with $t=0$ corresponding to 2016. In this expression, $W_{0} / Y_{0}$ is defined as the aggregate net private wealth to gross domestic product ratio, obtained from either the World Inequality Database (WID) or the OECD. ${ }^{22}$

Results. The results from this calculation are displayed in figure 2. Between 1950 to 2016, the compositional effect is positive in all countries, with an average increase of 80pp of GDP, and an increase of 105pp in the United States. These effects are quantitatively large. As a point of comparison, the actual changes in $W / Y$ that occurred over this period were 220pp for the average country with available data in the WID, and 118pp for the US.

Looking ahead from 2016 to 2100, the effects remain positive, are even larger on average, and are heterogeneous across countries, ranging from 48pp in Hungary to 237pp in China and 327pp in India, with a 147pp increase in the United States. In the high fertility

\footnotetext{
${ }^{20}$ For the present value of all DB wealth by age, we use estimates provided by Sabelhaus and Volz (2019), and we set the funded share to $37.5 \%$ to ensure consistency with the aggregate amount of non-federal funded defined benefit assets in the US economy. We exclude unfunded DB liabilities since they do not affect the level of wealth $a_{j 0}$ that goes into asset demand; conceptually, we instead think of unfunded DBs as a future transfer $t r_{j}$ in the household budget constraint (1). For the same reason, we do not include "social security wealth" in $a_{j 0}$ (Sabelhaus and Volz 2020, Catherine, Miller and Sarin 2020).

${ }^{21}$ Appendix C.2 shows that the results are robust to using different splitting rules, or to constructing income and wealth at the household level, and combining this with demographic projections for the age distribution of the heads of households.

${ }^{22}$ Net private wealth is defined as the sum of housing, business, and financial assets, net of liabilities, owned by households and nonprofit institutions serving households. Housing assets include the value of dwellings and land; financial assets include currency, bonds, deposits, equity, and investment fund shares, as well as life insurance and private pension funds. In appendix table A.1 we compare private wealth from aggregate data to the aggregated sum of individual survey wealth. In theory, these should be equal, by equation (2). In practice, when the two differ, equation (21) implicitly rescales wealth proportionately at each age so that the survey aggregate matches the WID or OECD total.
} 

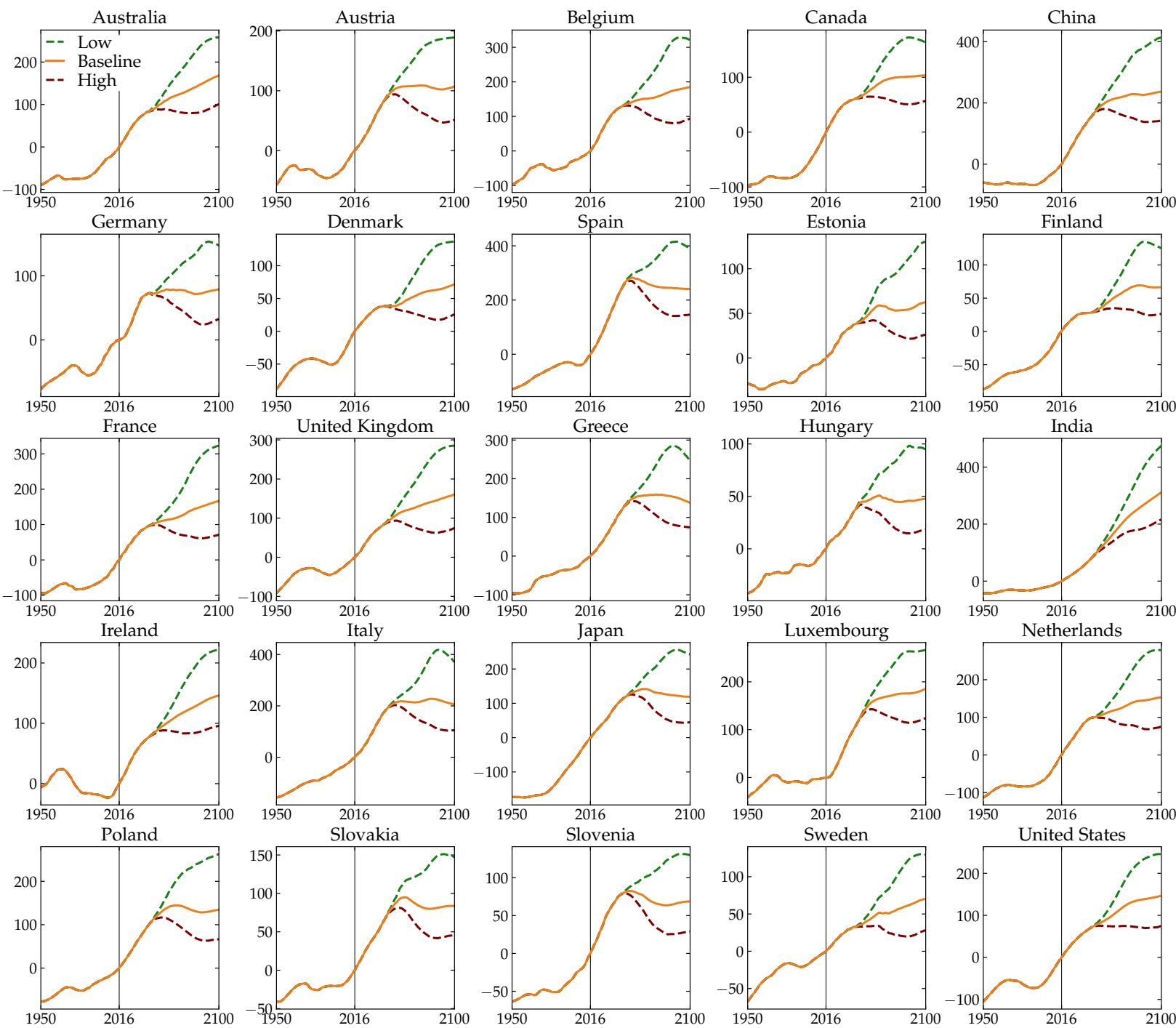

Figure 2: Predicted change in $W / Y$ from the compositional effect

Notes: This figure depicts the evolution of the predicted change in wealth-to-GDP from the compositional effect, calculated using equation (21) for $t=1950$ to 2100, reported in percentage points. The base year is 2016 (vertical line). The solid orange line corresponds to the medium fertility scenario from the UN, the dashed green line to the low fertility scenario, and the dashed red line to the high fertility scenario. 


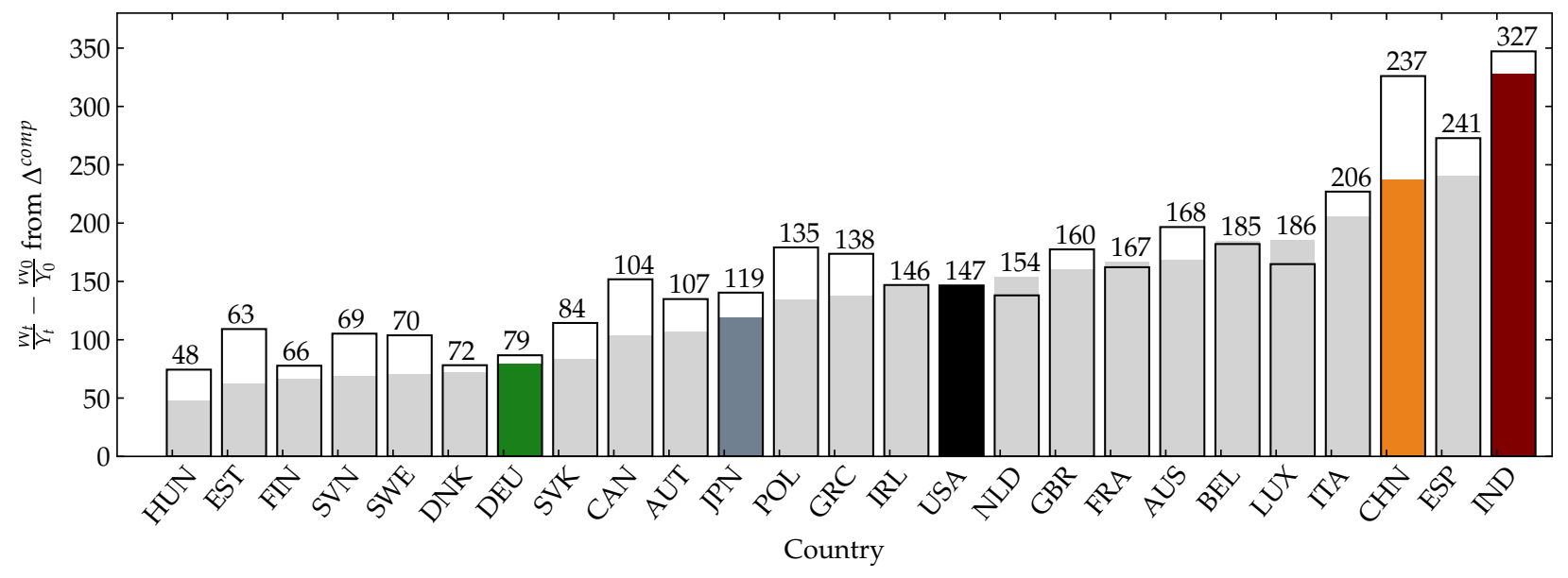

Figure 3: Compositional effects and contribution from demographics alone

Notes: The solid bars show, for each country, the predicted change in wealth-to-GDP from the compositional effect between 2016 and 2100 in pp, calculated using equation (21), and also reported on top of the bars. These values correspond to the end point of Figure 2. The transparent bars correspond to the case where $\Delta^{\text {comp }}$ in equation (10) is calculated using the US age profiles $a_{j 0}$ and $h_{j 0}$, but country-specific age distributions $\pi_{j t}$.

scenario, the effect is reduced by a younger population: it is brought down to 75pp in China and to 142pp in the United States; in contrast, the low fertility scenario sees even sharper aging, and the effect swells to 245pp in the United States and 447pp in China.

Figure 3 provides more detail on the heterogeneity across countries, with the solid bars displaying the predicted compositional change in $W / Y$ to 2100 for the main population scenario. In principle, this cross-country heterogeneity could reflect either differences in demographic evolution or differences in the age profiles of assets and labor income. While both matter, the former is the main factor: countries with large effects are those whose demographic transitions are later and faster. The transparent bars in figure 3 illustrate this by showing similar cross-country heterogeneity in compositional effects if we counterfactually assume that all countries have the same asset and income profile as the United States. $^{23}$

Unpacking the compositional effect: the case of the United States. The compositional effect reflects the interaction between population aging and the shapes of the wealth and income profiles. To help explain the magnitudes that we find, we study the case of the United States in greater detail.

The main mechanisms are summarized in figure 4 . The grey bars show the evolution

\footnotetext{
${ }^{23}$ By contrast, appendix figure A.4 shows that countries tend to experience similar compositional effects if they are all assumed to experience US demographics.
} 
A. Changing population distributions over a fixed 2016 age-wealth profile
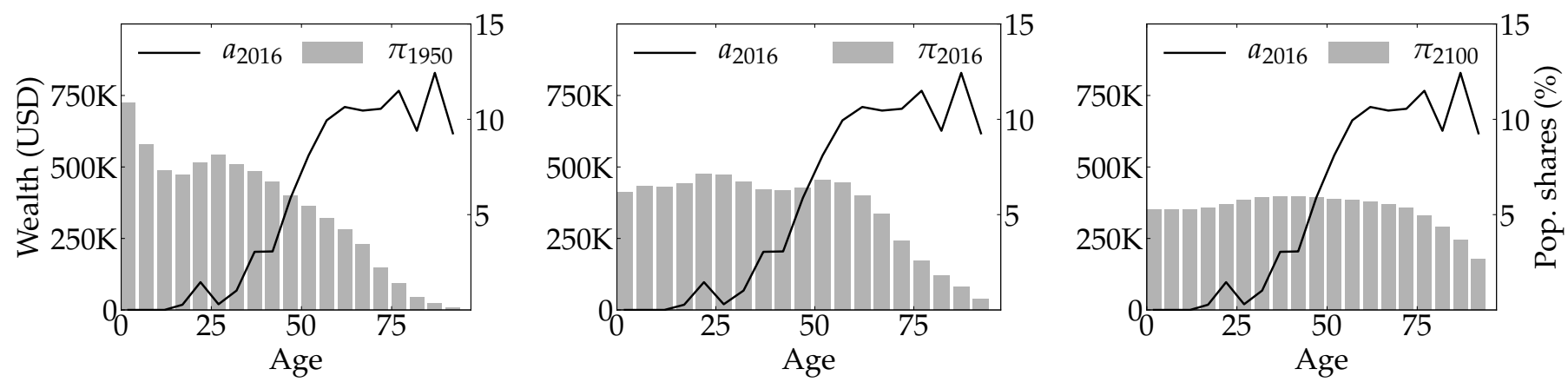

B. Changing population distributions over a fixed 2016 age-labor income profile
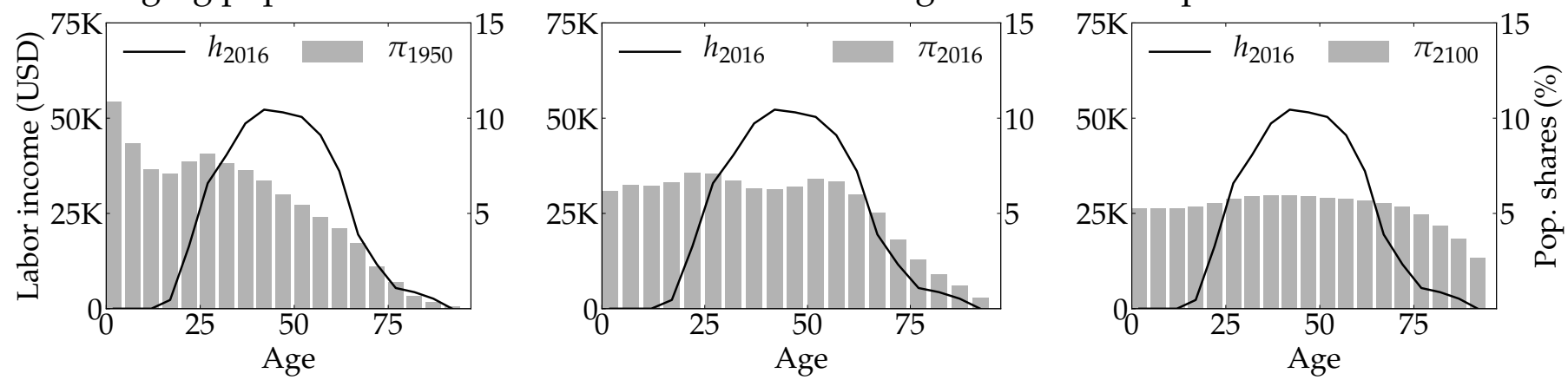

Figure 4: US age-wealth and labor income profiles with population age distributions

Notes: The solid lines in Panel A show the 2016 US age-wealth profiles from the SCF, expressed in current USD. The solid lines in panel B show the 2016 age-income profile from the LIS (CPS), expressed in current USD. Bars represent age distributions: 1950 age distribution in the left panels, 2016 age distribution in the middle panels, and 2100 age distribution in the right panels.

of the population distribution, starting young in 1950 and growing progressively older over time. In the figure, this population evolution is superimposed with the 2016 profiles of assets and labor income, with panel A illustrating how demographic change pushes up assets by moving individuals into high asset ages, and panel B illustrating how demographic change first pushes up aggregate labor income as the baby boomers reach middle age—the so-called "demographic dividend" (Bloom et al., 2003)—and later pushes down aggregate labor income as more individuals reach old age.

The total compositional effect can be separated into contributions from assets and labor supply using a first-order approximation of equation (10):

$$
\Delta_{t}^{\text {comp }} \simeq \underbrace{\frac{\sum\left(\pi_{j t}-\pi_{j 0}\right) a_{j 0}}{\sum \pi_{j 0} a_{j 0}}}_{\Delta_{t}^{\text {comp }, a}}+(\underbrace{-\frac{\sum\left(\pi_{j t}-\pi_{j 0}\right) h_{j 0}}{\sum \pi_{j 0} h_{j 0}}}_{\Delta_{t}^{\text {comp }, h}}) .
$$


A. Wealth profile effect

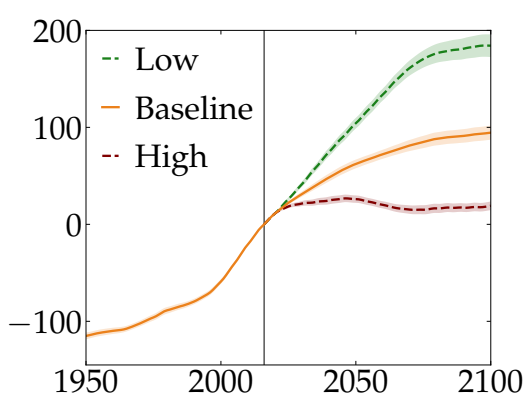

B. Income profile effect

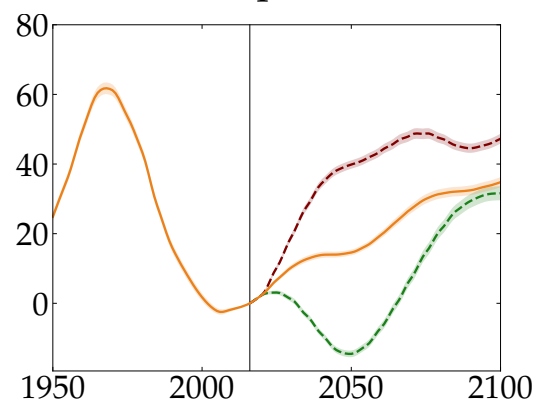

C. Compositional effect

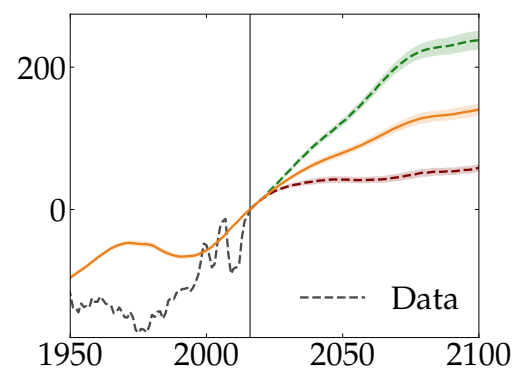

Figure 5: Effects of demographic composition on $W$ and $Y$ : United States 1950-2100

Notes: This figure shows the evolution of the two terms in equation (22). Panel A presents the contribution from the wealth profile, $\frac{W_{0}}{Y_{0}} \Delta_{t}^{c o m p, a}$. Panel B presents the contribution from the labor income profile, $\frac{W_{0}}{Y_{0}} \Delta_{t}^{c o m p}, h$. Panel C presents the overall compositional effect from equation (21), which is approximately equal to the sum of panel A and panel B, overlaid with historical data from the WID. In all graphs, the solid orange line corresponds to the baseline fertility scenario, the dashed green to the low fertility scenario, and the dashed red line to the high fertility scenario of the 2019 UN World Population Prospects. A bootstrapped $95 \%$ confidence interval is computed by resampling observations 10,000 times with replacement.

The terms $\Delta_{t}^{\text {comp,a }}$ and $\Delta_{t}^{\text {comp,h }}$ capture the covariances between the changes in age distribution on the one hand, and asset holdings and labor incomes on the other hand. $\Delta_{t}^{\text {comp, } a}$ is positive if the share of people in high asset ages increases, and $\Delta_{t}^{c o m p, h}$ is positive if the share of people in high labor income ages decreases. Since old people hold relatively more assets and work relatively less, aging eventually makes both terms positive.

Figure 5 displays the evolution of $\Delta_{t}^{\text {comp }, a}$ and $\Delta_{t}^{\text {comp, } h}$ (multiplied by $W_{0} / Y_{0}$ to obtain level effects on wealth-to-GDP). ${ }^{24}$ Panel A shows that $\Delta_{t}^{\text {compra }}$ monotonically pushes up the wealth-to-GDP ratio throughout the sample period. The trend flattens towards the end of the 21st century as aging becomes concentrated in very old ages where asset accumulation ceases. However, the trend never reverses, due to the well-known fact that asset decumulation in old age is quite limited. A large literature has debated the extent to which this limited decumulation reflects life-cycle forces, late-in-life-risks, or bequest motives (see e.g. Abel 2001, Ameriks and Zeldes 2004, De Nardi, French and Jones 2010, De Nardi, French, Jones and McGee 2021); our sufficient statistic result allows us to be agnostic about the exact cause within our given class of possible explanations. ${ }^{25}$

Panel B shows $\Delta_{t}^{\text {comp,h }}$ falling between 1970 and 2010 and then increasing through-

${ }^{24}$ Since $\frac{W_{0}}{Y_{0}}\left(e^{\Delta_{t}^{c o m p}}-1\right) \simeq \frac{W_{0}}{Y_{0}} \Delta_{t}^{c o m p} \simeq \frac{W_{0}}{Y_{0}} \Delta_{t}^{c o m p, a}+\frac{W_{0}}{Y_{0}} \Delta_{t}^{c o m p, h}$, the two effects approximately sum to the total predicted change from equation (21).

${ }^{25}$ Our benchmark model captures late-in-life risks if $\beta_{j}$ increases in old age. It rules out bequests, but when we allow for them in section 4, we find that the compositional effect remains the primary determinant of the effect on $W / Y$ at constant interest rates. 
out the rest of the 21st century, eventually adding 30pp to the wealth-to-GDP ratio. This non-monotonic pattern is a mirror image of the literature on the so-called "demographic dividend", which finds a non-monotonic output effect of aging as the population distribution moves across the hump-shaped profile of labor earnings (Bloom, Canning and Sevilla 2003; Cutler et al. 1990). Our findings complement this literature by connecting the output effect of demographics to an inverted effect on the wealth-to-GDP ratio. Quantitatively, this effect contributes a third of the full increase in $\Delta^{\text {comp }}$ for the United States between 2016 and 2100.

Our results relate to earlier findings by Poterba (2001), who used a shift-share analysis with population projections until 2050 and data from the 1983-1995 waves of the SCF to conclude that $\Delta^{\text {comp,a }}$ (which he called "projected asset demand") would be stable beyond 2020. He used this result to argue that an asset market meltdown was unlikely. In contrast to Poterba, we find a substantial increase in $\Delta_{t}^{\text {comp, },}$ throughout the remainder of the twenty-first century, reflecting our use of later SCF waves, and, more importantly, population projections with narrower age bins. In addition, Poterba's analysis abstracted from the labor supply term $\Delta^{\text {comp }, h}$, which we find is not trivial.

For other countries, the logic behind $\Delta^{\text {comp }}$ is broadly similar to that for the United States. In our online appendix ${ }^{26}$ we reproduce Figures 4 and 5 for all twenty-five countries in our sample. While each country has its own peculiarity-for instance, the timing of the demographic dividend is very uneven - in all of them, aging pushes individuals into higher-asset, lower-income age groups after 2050.

Robustness to base year and construction of age profiles. In using a single cross-section of asset and labor income profiles, our calculations rely on our model's property that age profiles are stable over time and grow at a constant rate $\gamma$. Given this feature, any crosssection will imply the same compositional effect, and cross-sectional estimates of $a_{j 0}$ and $h_{j 0}$ will agree with estimates of age effects from a time-age-cohort decomposition of repeated cross-sections, provided growth loads on time rather than on cohort effects.

In appendix C.2, we explore the effects of using different base years for the crosssectional profiles of labor income and asset holdings. For the United States, we use the twelve waves of the LIS going back to 1976, as well as 21 waves of the SCF going back to the 1950s. ${ }^{27}$ Calculating $\Delta_{t}^{\text {comp }}$ for all the 252 combinations of profiles, we find that the projections for 2016 to 2100 are very stable for all waves of the SCF going back to

\footnotetext{
${ }^{26}$ available at http://web.stanford.edu/ aauclert/demowealth21_country_appendix.pdf

${ }^{27}$ For the older waves, we use the SCF+ data developed in Kuhn, Schularick and Steins (2020), which harmonizes and reweights the historical SCF data to maximize the comparability with the modern waves of the SCF. We thank Amir Sufi for this suggestion.
} 
1989. If we use the profiles from even older waves, we find somewhat smaller effects: for instance, the log compositional effect $\Delta^{\operatorname{comp} p}$ is $20.8 \%$ with the oldest profiles, as opposed to $27.8 \%$ with the 2016 profiles. ${ }^{28}$ In contrast, using the age effects from our time-age-cohort decomposition on the 1989-2016 data leads to an even larger $\Delta^{\text {comp }}$ of $29.2 \%{ }^{29}$

Hence, while there is some variation across specifications, the effect is always large, positive, and of generally stable magnitude. In the appendix, we show that our results are also robust to using different methods of allocating household wealth to individuals.

\subsection{Asset supply and demand semielasticities}

We now turn to calculating the semielasticities of asset supply and demand using the formulas in proposition 2 and 4.

Asset supply semielasticity $\bar{\epsilon}^{s}$. The global asset supply semielasticity captures the response of the capital-output ratio to the required rate of return. ${ }^{30}$ Proposition 2 provides a closed-form solution for this semielasticity,

$$
\bar{\epsilon}^{s}=\frac{\eta}{r_{0}+\delta} \frac{\bar{K}_{0}}{\bar{W}_{0}}
$$

showing that $\bar{\epsilon}^{s}$ is proportional to the initial global capital-wealth ratio $\frac{\bar{K}_{0}}{\bar{W}_{0}}$, the inverse of the user cost of capital $r_{0}+\delta$, and the elasticity of substitution between capital and labor $\eta$. From our world economy calibration in section 4 , we obtain $\frac{\bar{K}_{0}}{\bar{W}_{0}}=0.78$ and $r_{0}+\delta=9.7 \%$. Given these numbers, $\bar{\epsilon}^{s}$ is between 4 and 12 for $\eta$ in a plausible range from 0.5 to 1.5 ; it is 8 with a Cobb-Douglas aggregate production function $(\eta=1)$.

Asset demand semielasticity $\bar{\epsilon}^{d}$. The global asset demand semielasticity reflects how much aggregate asset accumulation responds in the long-run to changes in $r$. Proposition 4 expresses $\epsilon^{c, d}$ in each country $c$ as a function of cross-sectional observables, the elasticity of intertemporal substitution (EIS) $\sigma$, and capital-labor substitution $\eta$. If $\sigma$ and $\eta$ are common across countries, these semielasticities aggregate as:

$$
\bar{\epsilon}^{d}=\sigma \cdot \bar{\epsilon}_{\text {substitution }}^{d}+\bar{\epsilon}_{\text {income }}^{d}+(\eta-1) \cdot \bar{\epsilon}_{\text {laborshare }}^{d}
$$

\footnotetext{
${ }^{28}$ Since $W / Y=4.28$ in 2016 , a $\log$ effect of $27.8 \%$ is the same as a level effect of $4.28\left(e^{0.278}-1\right)=137$ p.p.

${ }^{29}$ The choice of profiles matters more for the 1950-2016 compositional effect: there, the oldest profiles give an effect of $12.7 \%$, the newest profiles give an effect of $24.6 \%$, and the time-age-cohort decomposition gives an effect of $35.8 \%$.

${ }^{30}$ This reflects the absence of rents and the constant level of $B_{t} / Y_{t}$. If there are rents and debt-to-output responds to $r$, the responses of capitalized rents and debt to $r$ also affects $\bar{\epsilon}^{s}$
} 
where bars denote cross-country averages weighted by initial wealth levels.

Implementing the formulas for $\epsilon^{d, c}$ in proposition 4 using the terminal age distribution at 2100, we obtain $\bar{\epsilon}_{\text {substitution }}^{d}=39.5, \bar{\epsilon}_{\text {income }}^{d}=-2$ and $\bar{\epsilon}_{\text {laborshare }}^{d}=5.5$. Since $\bar{\epsilon}_{\text {substitution }}^{d}$ is positive and much larger than the other terms, $\bar{\epsilon}^{d}$ is positive unless the EIS is extremely low. ${ }^{31}$ When $\sigma$ has a reasonable value of 0.5 and the aggregate production function is Cobb-Douglas, $\bar{\epsilon}^{d}$ is around 18. This means that an exogenous decrease of the interest rate by one percentage point reduces the world wealth-to-GDP ratio by $18 \%$.

The formulas in proposition 4 rely on the distribution of consumption and wealth across different age groups $j$, as well as the "present value" equivalent distribution which discounts all values of the age group $j$ by $1 /(1+\hat{r})^{j}$, where $\hat{r}=\frac{1+r}{1+g}-1$ is the interest rate net of the economy's growth rate. We construct these distributions by weighting the wealth and consumption profiles by the long-run (2100) population distribution. The wealth profiles by age are obtained as in section 3 , and the consumption profiles are backed out from the household budget constraint (1) given the age profiles of wealth and income. ${ }^{32}$ The implied distributions are presented in appendix figure A.5.

The distributions can be used together with equation (16) to explain the forces behind our substitution and income effect terms. ${ }^{33}$ In (16), the substitution term is approximately a wealth-weighted average of $C / W$ times the variance of the age of consumption: since $C / W$ is around $1 / 6$ and consumption is approximately uniformly distributed between ages 20 and 80, a back-of-the-envelope calculation suggests that $\bar{\epsilon}_{\text {substitution }}^{d}$ is approximately $(80-20)^{2} /(12 \cdot 6)=50$, close to the actual value of 39.5. The income effect is approximately the difference between the average age of consumption and the average age of assets: since consumption on average occurs a few years before asset holdings, we obtain a negative, but relatively small, income effect.

Finally, our labor share term $\bar{\epsilon}_{\text {laborshare }}^{d}$ is the cross-country average of $\left(1-s_{L}\right) / s_{L}$. $1 /\left(r_{0}+\delta\right)$ weighted by wealth. The labor shares from our world economy calibration in section 4 are on average approximately $2 / 3$. Given $r_{0}+\delta=9.7 \%, \bar{\epsilon}_{\text {laborshare }}^{d}$ is roughly $\left(1-s_{L}\right) / s_{L} \cdot 1 /\left(r_{0}+\delta\right) \approx(1 / 2) \times 10=5$.

Comparison to existing empirical estimates. A number of papers have used variation in capital income taxes to estimate how asset accumulation responds to rates of return

\footnotetext{
${ }^{31}$ For example, with a Cobb-Douglas production function, $\bar{\epsilon}^{d}$ is positive when $\sigma \geq 2 / 39.5 \approx 0.05$, a relatively weak condition. In comparison, Achdou, Han, Lasry, Lions and Moll (2021) obtain $\sigma \geq 1$ as a sufficient condition for $\bar{\epsilon}^{d} \geq 0$ in a standard Aiyagari model.

${ }^{32}$ We use this indirect procedure, rather than consumption surveys directly, since the latter tend to be less comprehensive than wealth surveys and are not available for all countries in our study.

${ }^{33}$ Our exact implementation uses equations (18) and (19) and a country-specific $\hat{r}$, but in practice $\hat{r}$ is small enough in every country that expression (16) gives a useful approximation.
} 
(e.g. Kleven and Schultz 2014, Zoutman 2018, Jakobsen, Jakobsen, Kleven and Zucman 2020, Brülhart, Gruber, Krapf and Schmidheiny 2021). Reviewing this literature, Moll et al. (2021) identify a range for $\epsilon^{d}$ of 1.25 to $35 .{ }^{34}$ This range coincides closely with that implied by equation (24) for plausible values of $\sigma$ and $\eta$. None of the existing empirical estimates are negative, in line with our findings on substitution effects dominating income effects. In contrast to the infinite elasticity predicted by representative-agent models, or overlapping generations models with dynastic altruism motives (Barro 1974), all estimates are sufficiently small to imply that interest rates need to fall substantially to accommodate the large compositional effects in the data, as we quantify more precisely in the next section.

\subsection{General equilibrium implications}

We now put together our calculated compositional effects and semielasticities, using proposition 2 and 3 to obtain long-run general equilibrium changes. Here, we define the long run as 2100 .

The rate of return and wealth-to-GDP ratios. Proposition 2 shows that long-run changes in the rate of return and average wealth levels are functions of $\bar{\Delta}_{L R}^{\text {comp }}, \bar{\epsilon}_{L R}^{s}$, and $\bar{\epsilon}_{L R}^{d}$.

We estimate $\bar{\Delta}_{L R}^{\text {comp }} \equiv \sum_{c} \omega^{c} \Delta_{2100}^{c, \text { comp }}=32 \%$ by taking each country's compositional effects until 2100 from section 3.1, averaged using 2016 wealth levels. Equations (23) and (24) in section 3.2 express $\bar{\epsilon}_{L R}^{s}$ and $\bar{\epsilon}_{L R}^{d}$ in terms of capital-labor substitutability $\eta$ and the elasticity of intertemporal substitution $\sigma$. Our central estimate uses canonical values of $\eta=1$ and $\sigma=0.5$. Given the uncertainty surrounding the value of these parameters, however, we also consider a collection of lower and higher values. For the EIS, we consider a low value of $\sigma=0.25$ and a high value of $\sigma=1$, spanning the range typically considered in the macroeconomics literature (e.g. Havránek 2015). For capitallabor substitution, we consider a low value $\eta=0.6$ taken from Oberfield and Raval (2021), and a high value $\eta=1.25$ taken from Karabarbounis and Neiman (2014).

Table 1 presents our results. The left-hand panel shows the changes in the rate of return, calculated using equation (13), while the right-hand panel shows the average change in $\log$ wealth-to-GDP in percent, calculated using equation (14).

We find that the equilibrium return $r$ unambiguously falls in response to demographic change, refuting the "great demographic reversal" hypothesis (Goodhart and Pradhan,

\footnotetext{
${ }^{34}$ Moll et al. (2021) discuss the literature's implications for a slightly different semielasticity, $\partial \log W / \partial r$. Since underlying micro experiments (mostly wealth taxes) are unlikely to change $Y$ differentially across treatment and control, however, this should be equivalent to our $\epsilon^{d}=\partial \log (W / Y) / \partial r$.
} 
Table 1: Change in world interest rate and wealth-to-GDP

\begin{tabular}{cccccccc}
\hline \multicolumn{3}{c}{ A. $r_{L R}-r_{0}$} & & \multicolumn{3}{c}{ B. $\overline{\Delta_{L R} \log \left(\frac{W}{Y}\right)}$} \\
& & $\sigma$ & & & $\sigma$ \\
$\eta$ & 0.25 & 0.50 & 1.00 & & 0.25 & 0.50 & 1.00 \\
\cline { 2 - 4 } \cline { 6 - 8 } & -3.03 & -1.56 & -0.79 & & 14.6 & 7.5 & 3.8 \\
1.00 & -2.00 & $-\mathbf{1 . 2 3}$ & -0.70 & & 16.0 & $\mathbf{9 . 9}$ & 5.6 \\
1.25 & -1.65 & -1.09 & -0.65 & & 16.5 & 10.9 & 6.5 \\
\hline
\end{tabular}

Notes: This table presents predictions for the change in the total return on wealth $(r)$ and the wealthweighted $\log$ wealth-to-GDP $(W / Y)$ between $2016(t=0)$ and $2100(t=L R)$ using our sufficient statistic methodology. Columns vary the assumption on the elasticity of intertemporal substitution $\sigma$, rows vary the assumption on the elasticity of capital-labor substitution $\eta$. Central estimates are in bold. $r$ is expressed in percentage points, and wealth in percent $(100 \cdot \log )$.

2020). This result follows because $\bar{\Delta}_{L R}^{\text {comp }}$ and $\bar{\epsilon}^{s}+\bar{\epsilon}^{d}$ are both positive for any plausible combination of $\sigma$ and $\eta$. Intuitively, the compositional effect increases net asset demand, and if $\bar{\epsilon}^{s}+\bar{\epsilon}^{d}>0$, then a fall in $r$ is required to equalize the world's supply and demand of assets. ${ }^{35}$ In our central scenario, $r$ falls 123 basis points by the end of the twenty-first century; the fall is larger when $\sigma$ or $\eta$ are small, since this limits the responsiveness of asset supply and demand to falling returns. ${ }^{36}$

For our central scenario, average wealth-to-GDP increases by $10 \%$, or approximately 47 percentage points in levels as a share of GDP. While substantial, this increase is smaller than the average compositional effect of $32 \%$, since the equilibrium response from the compositional effect is dampened by a factor of $\bar{\epsilon}^{d} /\left(\bar{\epsilon}^{s}+\bar{\epsilon}^{d}\right) \simeq 1 / 3$, which is the share of adjustment occurring through increases in investment rather than through reductions in asset accumulation. Intuitively, whenever $\bar{\epsilon}^{d}>0$, the general equilibrium response is smaller than the compositional effect, since households accumulate fewer assets as interest rates fall. Wealth responses are larger when investment is elastic relative to accumulation; that is, when $\eta$ is large relative to $\sigma$.

Our finding of sizable but not radical increases in future wealth-to-GDP ratios lies between the predictions by Piketty and Zucman (2014) and Krusell and Smith (2015): Piketty and Zucman argue that a steadily lower population growth rate will lead to a

\footnotetext{
${ }^{35}$ In section 5, we explain why thinking of equilibrium in terms of flows rather than stocks can lead one to miss this conclusion. Our framework can also be extended to rationalize the effect of demographics in models in which agents hold different kinds of assets that command different returns (see e.g. Kopecky and Taylor 2020). If, for instance, the compositional effect of aging pushes up the net demand for safe assets, then the equilibrium safe return will tend to fall relative to the equilibrium risky return.

${ }^{36}$ Using numerical simulations, Papetti (2019) presents similar comparative statics. Appendix F.2 shows that the functional form implied by our sufficient statistic formulas fit his results very well.
} 


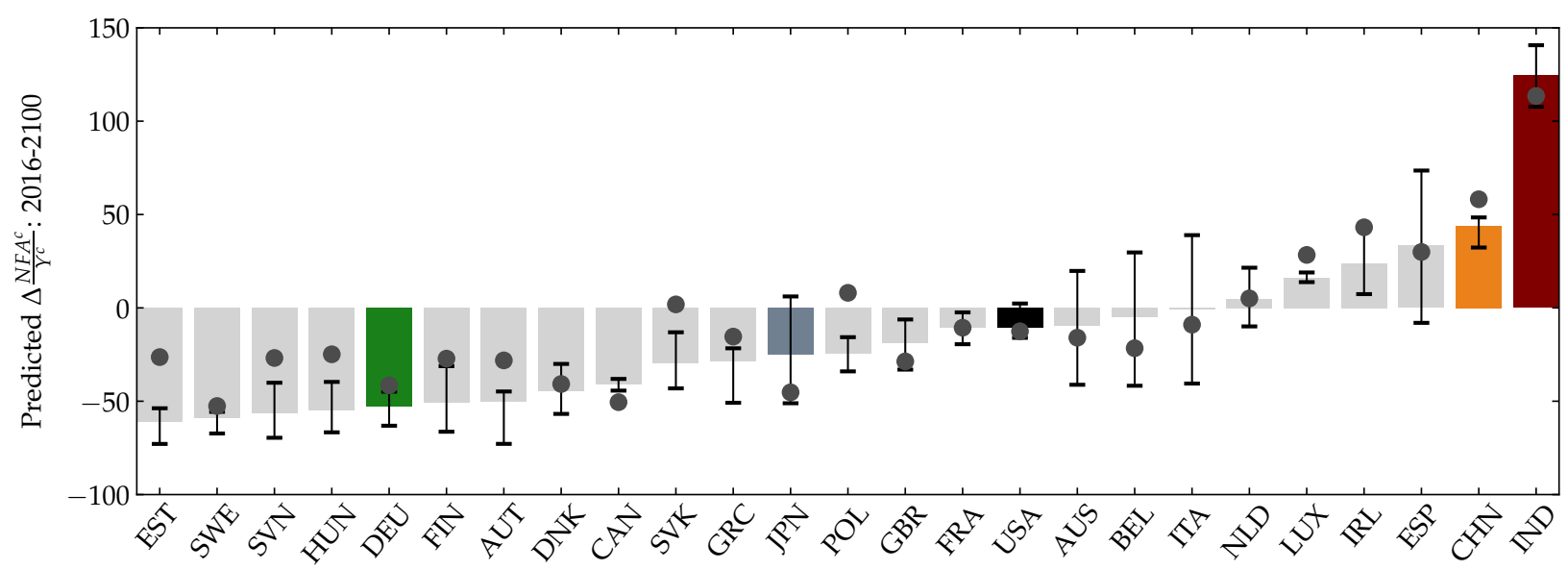

Figure 6: Long-run NFAs under alternative assumptions for $\sigma$ and $\eta$

Notes: This figure presents predictions for NFAs using our sufficient statistic methodology. The solid bars report $\Delta_{L R} N F A^{c} / Y^{c}$ calculated by applying equation (15), assuming $\sigma=0.5$ and $\eta=1$. The confidence intervals correspond to the maximum and the minimum value obtained from this formula across all possible combinations of $\sigma$ and $\eta$ considered in Table 1. The dots correspond to the demeaned compositional effect, $\Delta_{L R}^{c o m p, c}-\bar{\Delta}_{L R}^{c o m p}$, the first term in equation (15), which is independent of $\sigma$ and $\eta$.

surge in $W / Y$ in the twenty-first century, ${ }^{37}$ while Krusell and Smith argue that the predictions from representative agent models of no change in $W / Y$ are more consistent with empirical responses of savings rates to changes in the growth rate.

Global imbalances. Next, we turn to the evolution of net foreign asset positions. Figure 6 shows the changes between 2016 and 2100 predicted by the formula in proposition 3. The bars display the main results, which feature a large divergence in NFA positions, with India and China experiencing increases of 44 to 125 percentage points and Germany experiencing a decrease of 55 percentage points.

The large divergence of NFAs mainly reflects the large heterogeneity in compositional effects found in section 3.1. By proposition 3, this heterogeneity affects global imbalances through the demeaned compositional effects $\Delta_{L R}^{c o m p, c}-\bar{\Delta}_{L R}^{c o m p}$, whose direct implications for NFAs (assuming no heterogeneity in $\epsilon^{\mathcal{s}}$ and $\epsilon^{d}$ ) are plotted as circles in figure 6 . The demeaned compositional effects broadly mirror the predicted changes in NFAs.

Compared to the results on $r$ and wealth, the results on global imbalances are less sensitive to the value of the elasticities $\eta$ and $\sigma$. As proposition 3 shows, semielasticities only affect global imbalances insofar as they differ across countries. Since changing $\eta$ and $\sigma$ primarily moves semielasticities in parallel across countries, they have a relatively

\footnotetext{
${ }^{37}$ According to Piketty and Zucman, $W / Y=s / g$ fits the historical data quite well with a stable savings rate $s$. If $g$ falls from $1.5 \%$ to $1 \%$, consistent with a $0.5 \%$ forecasted decline in population growth to 2100 , then their model predicts a $\log$ increase in $W / Y$ of $\log (1.5)=40 \%$
} 
A. NFA projection

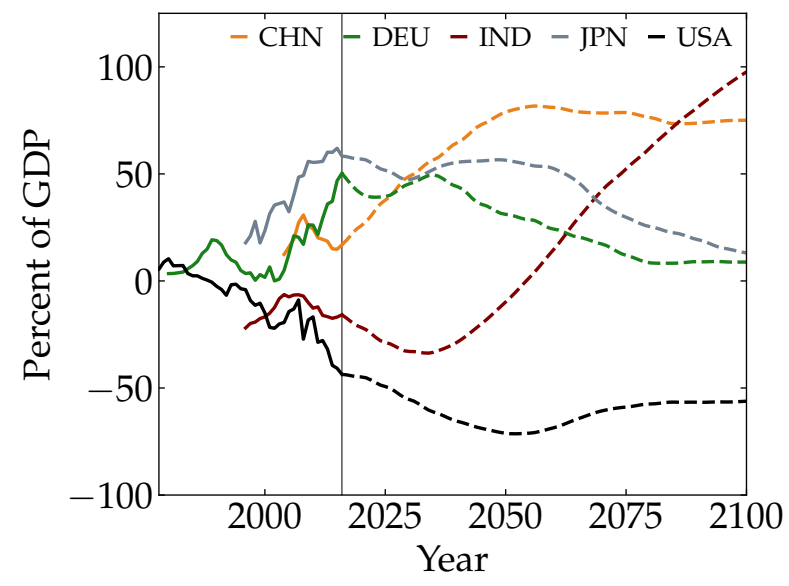

B. Historical performance

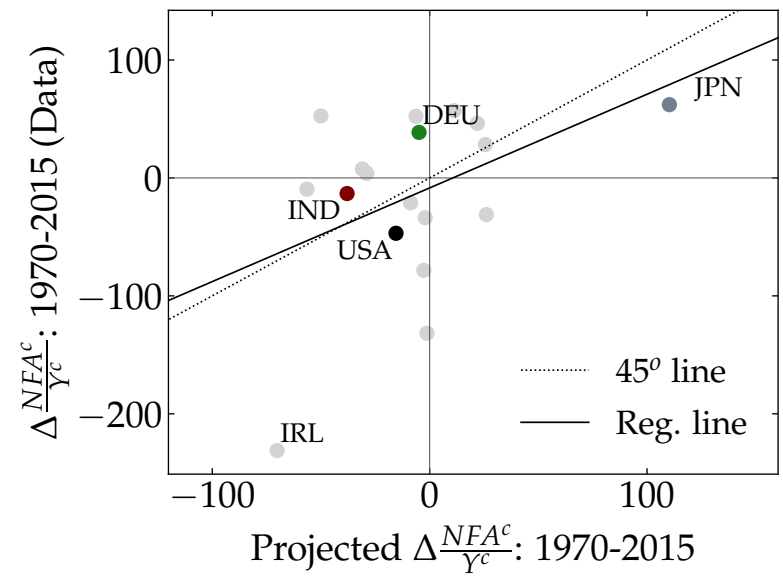

1

Figure 7: Using the demeaned compositional effect to project NFAs

Notes: Panel A projects NFA-to-GDP ratios between 2016 and 2100 from demeaned compositional effects, using equation (25). Solid lines are historical developments from figure 1. Panel B shows the projection from the demeaned compositional effect (x-axis) against the actual change in NFA between 1970 and 2015 (y-axis) for the 18 countries for which the data is available. (Source: Lane and Milesi-Ferretti 2017). The dotted line is a $45^{\circ}$ line, the solid line is the ordinary least squares regression line.

limited effect on the differences across countries. In the figure, the confidence bands show the minimum and the maximum prediction as $\eta$ and $\sigma$ parameters are varied in the range considered above. With a few exceptions, these bands are quite tight.

The importance of demeaned compositional effects suggests a dynamic projection for NFAs that simply uses the demeaned compositional effect at each point in time: ${ }^{38}$

$$
\Delta \frac{N F A_{t}^{c}}{Y_{t}^{c}} \simeq \frac{W_{0}^{c}}{Y_{0}^{c}}\left(e^{\left(\Delta_{t}^{c o m p, c}-\bar{\Delta}_{t}^{c o m p}\right)}-1\right)
$$

Panel A of figure 7 implements this calculation. The solid lines show global imbalances until today for the five large economies discussed in the introduction, and the dashed lines show the projections from equation (25). In the next few decades, we expect to see a widening of existing global imbalances: China's net foreign assets will rise substantially, while those of the US will decline. Although these trends flatten mid-century, the second half of the 21st century features a conspicuous rise in India's net foreign assets, offset partly by a decline in Germany and Japan, whose demographic transitions at that point are nearly complete. These results trace back to the heterogeneity in compositional effects that we documented in section 3.1, which showed China and India with very large $\Delta_{t}^{\text {comp,c }}$

\footnotetext{
${ }^{38}$ Appendix figure A.6 instead applies equation (15) at each point, taking into account the interest rate adjustment and the heterogeneity in elasticities across countries.
} 
relative to the world average.

To conclude this section, we explore how well equation (25) captures historical variations in NFAs. The results are shown in panel B in figure 7, with the horizontal axis showing the change in NFAs between 1970 and 2015 predicted by (25), and the vertical axis showing the actual changes. For such a simple exercise, the two line up quite well: for instance, Japan had the highest projected rise in its NFA, of around 100pp of GDP, which is actually what occurred over this period. The regression line of actual on predicted NFA changes is close to the 45 degree line. Of course, non-demographic forces are also at play in explaining NFA developments over this period of time-including valuation effects from fluctuations in nominal exchange rates and relative stock market performance, as well as inflows into Ireland due to its growing status as a tax haven. ${ }^{39}$ But this exercise suggests that demographic change, as captured by compositional effects, is in fact an important driver of global imbalances looking backward. This echoes earlier findings from the structural demographics literature (e.g. Backus et al. 2014 and Bárány et al. 2019).

\section{The compositional effect in a quantitative model}

In our sufficient statistic analysis so far, we predicted equilibrium outcomes from a small set of parameters and data moments. The underlying model in section 2 was rich in some respects, but it also abstracted from a number of forces that the quantitative demographics literature has found to be important to explain savings: bequest motives, changing mortality, and changes in government taxes, transfers, and retirement policy.

In this section, we extend the baseline model to incorporate these features. We simulate this model numerically, and study how well the sufficient statistic analysis holds up. We find that it remains an excellent guide, both qualitatively and quantitatively. The main exception is when the fiscal adjustment in response to an aging population is one-sided: if the budget is balanced entirely with higher taxes, the aggregate effects of aging become uniformly smaller, while if it is balanced entirely with lower benefits, the effects become uniformly larger.

\subsection{Extending the model of section 2}

The basic setup is the same as in section 2. Below we outline the main new features, and provide details in appendix D.1. We continue to omit the country superscript $c$ unless

\footnotetext{
${ }^{39}$ On the importance of valuation effects for NFAs, see Gourinchas and Rey (2007) and Atkeson, Heathcote and Perri (2021). On the importance of tax havens, see Zucman (2013) and Coppola, Maggiori, Neiman and Schreger (2021)
} 
there is a risk of ambiguity.

For the production sector, we now assume that $F$ is a CES production function with elasticity $\eta$. We make two modifications to the specification of demographics: survival rates $\phi_{j t}$ can vary over time, and there is an exogenous number of migrants $M_{j t}$ of age $j$ at time $t$.

To allow for a longer working life, we introduce a time-varying retirement policy $\rho_{j t}$. We also introduce bequests governed by non-homothetic preferences, which help explain asset inequality and the limited decumulation of assets at old ages. We remove annuity markets given their limited share in aggregate wealth; individuals self-insure against mortality risks, with assets remaining at death given as bequests. Last, we assume that there is intergenerational transmission of ability. These are all standard features of quantitative OLG models (e.g. De Nardi 2004).

The new individual problem is

$$
\begin{aligned}
\max \mathbb{E}_{k} \sum_{j=0}^{J} \beta_{j} \Phi_{j t}\left[\frac{c_{j t}^{1-\frac{1}{\sigma}}}{1-\frac{1}{\sigma}}+\mathrm{Y} Z_{t}^{v-\frac{1}{\sigma}}\left(1-\phi_{j t}\right) \frac{\left(\mathfrak{a}_{j t}\right)^{1-v}}{1-v}\right] \\
\text { s.t. } \quad c_{j t}+\mathfrak{a}_{j+1, t+1} \leq w_{t}\left(\left(1-\tau_{t}\right) \ell_{j t}\left(z_{j}\right)\left(1-\rho_{j t}\right)+\operatorname{tr} r_{j t}\left(z_{j}\right)\right)+\left(1+r_{t}\right)\left[\mathfrak{a}_{j, t}+b_{j t}^{r}\left(z_{j}\right)\right] \\
\mathfrak{a}_{j+1, t+1} \geq-\bar{a} Z_{t} .
\end{aligned}
$$

Compared to the setup in section 2, the second term in the utility function captures preferences for bequests. Bequest preferences have curvature $v \leq \frac{1}{\sigma}$ to allow for nonhomotheticity, and are scaled with a constant $Y$, mortality risk $1-\phi_{j t}$, and a term $Z_{t}^{v-\frac{1}{\sigma}}$ that makes this non-homotheticity consistent with balanced growth. In the budget constraint, $b_{j t}^{r}\left(z_{j}\right)$ denotes bequests received. The factor $\rho_{j t} \in[0,1]$ denotes retirement policy, and specifies how much labor individuals of age $j$ are allowed to supply at time $t$.

The individual state $z_{j}$ consists of a permanent component $\theta$, which is Markov across generations, and a transient component $\varepsilon_{j}$, which is Markov across years, both normalized to have mean 1. Total labor supply is the product of these two components and a deterministic age profile: $\ell_{j t}\left(z_{j}\right)=\theta \varepsilon_{j} \ell_{j}$. Bequests received $b_{j t}^{r}\left(z_{j}\right)$ are obtained from pooling all bequests from parents of each type $\theta$, distributing them across ages $j$ in proportion to a fixed factor $F_{j}$, and across types $\theta^{\prime}$ in proportion to the intergenerational transition matrix of types $\Pi\left(\theta^{\prime} \mid \theta\right)$.

For government policy, we assume that transfers reflect the social security system and are given by $\operatorname{tr}_{j t}\left(z_{j}\right)=\rho_{j t} \theta d_{t}$, where $d_{t}$ denotes the time-varying replacement rate. The government policy consists of a sequence of retirement policies $\left\{\rho_{j t}\right\}$ and a fiscal rule 
that targets an eventually converging sequence of government debt $\left\{\frac{B_{t}}{Y_{t}}\right\}$, where the debt sequence is obtained by dynamically adjusting replacement rates $d_{t}$, taxes $\tau_{t}$ and consumption $G_{t}$.

\subsection{Asset demand and supply in the extended model}

Unlike in the baseline model of section 2, demographic change in our extended model affects individual asset accumulation and labor supply decisions even for a fixed $r$ by generating variation over time in received bequests $\tilde{b}_{j t}^{r}(\theta)$, survival rates $\phi_{j t}$, tax and benefit policy $\left\{\tau_{t}, d_{t}\right\}$, and retirement policy $\rho_{j t}$. These changes create non-compositional effects on the wealth-to-GDP ratio, and imply that propositions 2 and 3 no longer hold, since these propositions relied on the compositional effect summarizing all effects of demographics.

However, the asset demand and supply framework underpinning these propositions still applies to the extended model, provided that we replace the compositional effect $\Delta_{t}^{\text {comp,c }}$ with the more general notion of a small-open-economy effect $\Delta_{t}^{\text {soe,c }}$. This effect is defined as the change in the wealth-to-GDP ratio for a small open economy facing a fixed $r$ over time, with $\Delta^{\text {soe }}-\Delta^{\text {comp }} \neq 0$ indicating that non-compositional effects are present. We can then prove the following.

Proposition 5. If the wealth holdings of agents start in a steady-state distribution given $r_{0}$ and $\pi_{0}^{c}$, then proposition 2 and 3 hold in the extended model, with $\Delta^{\text {comp,c }}$ replaced by $\Delta^{\text {soe, } c}$, where $\Delta_{t}^{\text {soe,c }}$ is defined as the change in the wealth-to-GDP ratio between 0 and $t$ in a small open economy equilibrium with a constant rate of return $r_{0}$.

Proof. See appendix D.2.

Proposition 5 provides a general framework for interpreting the effects of demographics. In appendix F.1, we use this framework to analyze the findings in Eggertsson et al. (2019) (EMR) and Gagnon et al. (2021) (GJLS), two recent papers that find very different effects of demographics on the real interest rate from 1970 to 2015 . EMR's much larger effect is explained primarily by a compositional effect that is much larger in the model than in the data, driven both by a steep age-wealth profile and by an overestimated change in the age composition of the population. ${ }^{40}$

The next two sections calibrate our model and interpret the results through the lens of proposition 5 .

\footnotetext{
${ }^{40} \mathrm{EMR}^{\prime}$ s lower semielasticities, especially a low $\epsilon^{\mathcal{S}}$, also play some role.
} 


\subsection{Calibration}

We calibrate a world economy consisting of the 25 economies from section 3 . To obtain parameters for each country, we calibrate a steady-state version of our model to 2016 data. Starting from this steady state, we then simulate the model from 2016 onward given demographic projections.

Steady-state calibration procedure Appendix D.3 spells out the steady-state version of our model, which for the most part is standard. ${ }^{41}$ The main calibration parameters and results are displayed in table 2. For parameters that are common across countries, the "All" column displays the world value. Country-specific parameters have a c-superscript, and the US values are displayed for illustration. Below we summarize the main elements of the calibration, with some supplemental information in appendix D.4.

The real rate of return $r$ is the 2016 value from figure 1 in the introduction, with the calculation described in appendix A. For the wealth-to-GDP ratio $W^{c} / Y^{c}$, we use the same data as in section 3 . We use data from the IMF to obtain country-specific debt levels $B^{c} / Y^{c}$ and net foreign asset positions $N F A^{c} / Y^{c}$, adjusted to ensure that $\sum_{c} N F A^{c}=0$. The capital-output ratio is obtained residually as $K^{c} / Y^{c}=W^{c} / Y^{c}-B^{c} / Y^{c}-N F A^{c} / Y^{c}{ }^{42}$

On the production side, we set the elasticity of substitution between labor and capital to unity, $\eta=1$. Countries have a common labor-augmenting growth rate $\gamma$ calibrated to the average growth in output per labor unit $\frac{Y_{t}^{c}}{L_{t}^{c}}$ between 2000 and 2016. The common depreciation rate is calibrated to match aggregate capital consumption from the Penn World Table given the capital stocks calibrated above. Given these parameters, we obtain the investment to output ratio and the labor share in each country from $\frac{K^{c}}{Y^{c}}$ and the countryspecific growth rate $g^{c} \equiv\left(1+n^{c}\right)(1+\gamma)-1$.

For government policy, we assume that all countries have a discrete retirement policy, with $\rho_{j}^{c}=0$ for $j<J^{r, c}$ and $\rho_{j}^{c}=1$ for $j \geq J^{r, c}$, where $J^{r, c}$ is the retirement age. The retirement age is calibrated to the effective age of labor market exit, which we define using information from the OECD and the labor income profiles. ${ }^{43}$ We define the income tax

\footnotetext{
${ }^{41}$ The main non-standard element is a counterfactual flow of migrants, which we introduce to ensure that the steady state implied by the 2016 birth and death rates can exactly match the observed age distribution in 2016. This method is similar to the one used in Penn Wharton Budget Model (2019), and is one way to address a generic problem in the calibration of steady-state demographic models, which is that observed mortality and population shares are generally inconsistent with a stationary population distribution. This adjustment is only needed in the steady state: to simulate the dynamics after 2016, we use the migration flows given in demographic projections.

${ }^{42}$ Note that the implied $K / Y$ for the US is high relative to standard measures of capital stock. Our methodology implicitly assumes that unmeasured capital accounts for this gap. An alternative procedure would be to explain the gap using markups.

${ }^{43}$ Our main source is the OECD's data on "effective age of labor market exit" from the OECD Pensions at
} 
Table 2: Calibration parameters

\begin{tabular}{|c|c|c|c|c|}
\hline Parameter & Description & US & All & Source \\
\hline \multicolumn{5}{|c|}{ Demographics } \\
\hline$J^{w}, J$ & Initial and terminal ages & & 20,95 & \\
\hline$n^{c}$ & Population growth rate & $0.6 \%$ & & UN World Population Prospects \\
\hline$\pi_{j}^{c}$ & Population distribution & & & UN \\
\hline$\phi_{j}^{c}$ & Survival probabilities & & & UN \\
\hline \multicolumn{5}{|c|}{ Returns and assets } \\
\hline$r$ & Real return on wealth & & $3.9 \%$ & Described in appendix A \\
\hline$W^{c} / Y^{c}$ & Total wealth over GDP & $438 \%$ & & WID \\
\hline$B^{c} / Y^{c}$ & Debt over GDP & $106.8 \%$ & & IMF \\
\hline$N F A^{c} / Y^{c}$ & Net foreign assets & $-35.8 \%$ & & IMF \\
\hline$K^{c} / Y^{c}$ & Capital over GDP & $367 \%$ & & $\frac{W^{c}}{Y^{c}}-\frac{B^{c}}{Y^{c}}-\frac{N F A^{c}}{Y^{c}}$ \\
\hline \multicolumn{5}{|c|}{ Production side } \\
\hline$I^{c} / Y^{c}$ & Investment over GDP & $30.9 \%$ & & $\frac{K^{c}}{Y^{c}}\left(\delta+g^{c}\right)$ \\
\hline$\alpha^{c}$ & Constant in prod. fn. & 0.356 & & $(r+\delta)\left(\frac{K^{c}}{Y^{c}}\right)^{\frac{1}{\eta}}$ \\
\hline$s^{L, c}$ & Labor share & 0.64 & & $1-(r+\delta) \frac{K^{c}}{Y^{c}}$ \\
\hline$\delta$ & Depreciation rate & & $5.79 \%$ & $\sum_{c} \delta^{c} K^{c}(\mathrm{PWT})$ divided by $\sum_{c} K^{c}$ \\
\hline$\gamma$ & Technology growth & & $2.03 \%$ & World average 2000-16 from $\frac{Y_{t}}{\sum N_{i t} h_{j 0}}$ \\
\hline$\eta$ & $K / L$ elasticity of subst. & & 1 & Standard \\
\hline \multicolumn{5}{|c|}{ Government policy } \\
\hline$J^{r, c}$ & Retirement age & 66 & & OECD \\
\hline$G^{c} / Y^{c}$ & Consumption over GDP & $12.5 \%$ & & Government budget \\
\hline $\bar{d}^{c}$ & Social security benefits & $71.3 \%$ & & Benefits-to-GDP from OECD \\
\hline$\tau^{c}$ & Labor tax rate & $31.6 \%$ & & Balanced total budget \\
\hline \multicolumn{5}{|c|}{ Income process } \\
\hline$\chi_{\epsilon}$ & Idiosyncratic persistence & & 0.91 & Auclert and Rognlie (2018) \\
\hline$v_{\epsilon}$ & Idiosyncratic std. dev. & & 0.92 & Auclert and Rognlie (2018) \\
\hline$\chi_{\theta}$ & Intergenerational persist. & & 0.677 & De Nardi (2004) \\
\hline$v_{\theta}$ & Intergenerational std. dev. & & 0.61 & De Nardi (2004) \\
\hline$\underline{a}$ & Borrowing limit & 0 & & \\
\hline \multicolumn{5}{|l|}{ Preferences } \\
\hline$\sigma$ & EIS & & 0.5 & Standard \\
\hline $\bar{\beta}^{c}$ & Discount factor process & 1.044 & & See text \\
\hline$\xi^{c}$ & Discount factor process & 0.00063 & & See text \\
\hline $\mathrm{Y}^{c}$ & Bequests scaling factor & 67.95 & & See text \\
\hline$v$ & Bequest curvature & & 1.32 & See text \\
\hline
\end{tabular}


rate $\tau$ using OECD data on the average tax wedge on personal earnings. Transfers capture the social security system, and satisfy $\operatorname{tr}^{c}\left(z_{j}\right)=\rho_{j} \theta d^{c}$, where we calibrate the social security system replacement rate $d^{c}$ by targeting country-specific benefit-to-GDP ratios net of taxes from the OECD Social Expenditure Database. Government consumption $G^{c} / Y^{c}$ is adjusted to ensure a constant debt-to-output ratio.

For the income process, we use average labor income by age to target the deterministic component of labor supply $\bar{\ell}_{j}$ for all ages before retirement, $j<J^{r, c}$. ${ }^{44}$ For the idiosyncratic term $z$, the log transient component follows an $\mathrm{AR}(1)$ process over the life-cycle, and the log permanent component follows an AR(1) process across generations. The parameters of these processes are taken from Auclert and Rognlie (2018) and De Nardi (2004). We assume that the distribution of bequests received across ages $F_{j}$ is common across countries, and we match it to the age distribution of bequests received in the Survey of Consumer Finances.

The remaining parameters are the elasticity of intertemporal substitution $\sigma$, the time preference profile $\beta_{j}$, and the weight and curvature on bequests $(Y, v)$. We assume that parameters $\sigma, \mathrm{Y}$ and $v$ are common across countries. To match country-specific agewealth profiles, we allow the level shifters $\beta_{j}$ to vary across countries according to a quadratic formula, $\log \beta_{j}^{c}=-j \times \log \bar{\beta}^{c}+\xi^{c}(j-40)^{2}$, where $\xi^{c}=0$ corresponds to exponential discounting. Our calibration first sets $\sigma$ to 0.5 in line with section 3. To discipline the common $\mathrm{Y}$ and $v$, we set them jointly with the parameters of US time discount values $\beta_{j}^{U S}$ to minimize the squared distance to the US profile of wealth by age and the bequestto-GDP ratio, subject to the constraint of precisely matching the US aggregate wealth to GDP ratio. ${ }^{45}$ For all other countries, we set $\beta^{c}$ and $\xi^{c}$ to fit the profile of wealth by age, again subject to the constraint of exactly matching the wealth-to-GDP ratio.

Table 3 summarizes calibration outcomes for the 12 largest economies. The successful fit of the long-run compositional effect $\Delta^{\operatorname{comp}, c}$ reflects the good fit of the labor and wealth profiles. In the appendix, we provide additional information about the calibration, including the fit of labor and wealth profiles and the main parameters for all 25 economies.

a Glance guide. In seven countries, the age provided by the OECD implies that labor market exit happens after the age at which aggregate labor income falls below implied benefit income. In those cases, we define the latter age as the date of labor market exit. See the appendix for details.

${ }^{44}$ For $j \geq J^{r, c}, \bar{\ell}_{j}$ is calibrated from age- $j$ labor earnings, scaled up by $\frac{L F P R_{r}, c}{L F P R_{j}}$ to compensate for labor force participation at $j$ being depressed by retirement. Since $\left(1-\rho_{j}\right) \bar{\ell}_{j}=0$ for all $j \geq J^{r, c}$, this value does not matter for steady state, but will matter in simulations where the retirement is increased.

${ }^{45}$ The US bequest-to-GDP ratio is from Alvaredo, Garbinti and Piketty (2017), and in the appendix, we also validate the model to the inequality of bequests taken from Hurd and Smith (2002). 
Table 3: World economy calibration

\begin{tabular}{lccccccc}
\hline & \multicolumn{3}{c}{$\Delta^{\text {comp }, c}$} & \multicolumn{3}{c}{ Components of wealth } & \multicolumn{2}{c}{ Government policy } \\
Country & Model & Data & $\frac{W^{c}}{Y^{c}}$ & $\frac{B^{c}}{Y^{c}}$ & $\frac{N F A^{c}}{Y^{c}}$ & $\tau^{c}$ & $\frac{B e n^{c}}{Y^{c}}$ \\
\hline AUS & 30 & 29 & 5.09 & 0.40 & -0.46 & 0.29 & 0.04 \\
CAN & 21 & 20 & 4.63 & 0.92 & 0.20 & 0.31 & 0.04 \\
CHN & 47 & 45 & 4.20 & 0.44 & 0.25 & 0.30 & 0.04 \\
DEU & 21 & 20 & 3.64 & 0.69 & 0.58 & 0.50 & 0.10 \\
ESP & 42 & 37 & 5.33 & 0.99 & -0.74 & 0.39 & 0.10 \\
FRA & 31 & 30 & 4.85 & 0.98 & -0.05 & 0.48 & 0.13 \\
GBR & 27 & 26 & 5.35 & 0.88 & 0.08 & 0.31 & 0.06 \\
IND & 65 & 56 & 4.16 & 0.68 & -0.08 & 0.30 & 0.01 \\
ITA & 34 & 30 & 5.83 & 1.31 & -0.02 & 0.48 & 0.13 \\
JPN & 24 & 22 & 4.85 & 2.36 & 0.66 & 0.32 & 0.09 \\
NLD & 34 & 33 & 3.92 & 0.62 & 0.70 & 0.37 & 0.05 \\
USA & 32 & 29 & 4.38 & 1.07 & -0.36 & 0.32 & 0.06 \\
\hline
\end{tabular}

Notes: This table presents key initial (2016) steady state statistics for the 12 largest economies by GDP. The first two columns show the value of the compositional effect $\Delta^{c o m p, c}$ in both the model and the data, expressed in percent $(100 \cdot \log )$. The next columns report the wealth-to-GDP ratio $W / Y$, government debtto-GDP ratio $B / Y$, and NFA-to-GDP ratio $N F A / Y$. The final two columns report the average tax wedge on labor income $\tau$ and retirement-benefit-to-GDP ratio Ben $/ Y$. Data sources are given in the main text.

\subsection{Simulations and results}

The steady-state calibration pins down the individual parameters, the production parameters, and the initial state of all economies. To study the effect of demographic change, we feed the economy with paths for all demographic variables from the UN World Population Prospects for 2016 to 2100, assuming a smooth transition to a long-run world demographic steady state from that point onwards. ${ }^{46}$ We are interested in how wealth levels, rates of return, and net foreign asset positions evolve, and how this evolution relates to our findings from section 3.

Formally, we assume that the world economy has reached a stationary equilibrium in 2300 and we solve for the transition dynamics between 2016 and 2300. Our experiments hold preferences and the aggregate production function constant, but government policy instruments change over time as aging creates fiscal shortfalls that need to be compensated. In our main specification, we assume that the retirement age in all countries increases by one month per year over the first 60 years of the simulation (in line with CBO's projection for the US), and that the government operates a fiscal rule that keeps the debt-to-output ratio constant by relying equally on tax increases, benefit cuts, and

\footnotetext{
${ }^{46}$ See appendix D.5 for details about our assumptions for the demographic transition after 2100.
} 
Table 4: Baseline and extended model results: 2016-2100

\begin{tabular}{lcc|ccccc}
\hline & $\Delta r$ & $\bar{\Delta} \log \frac{W}{Y}$ & $\bar{\Delta}^{\text {comp }}$ & $\bar{\Delta}^{\text {soe }}$ & $\bar{\epsilon}^{d}$ & $\bar{\epsilon}^{s}$ \\
\hline Sufficient statistic analysis & -1.23 & 9.9 & 31.8 & & 17.8 & 8.0 \\
Preferred model specification & -1.23 & 10.3 & 34.1 & 30.3 & 17.1 & 8.0 \\
\hline Alternative model specifications & & & & & & \\
$\quad+$ Constant bequests & -1.18 & 10.0 & 34.1 & 27.0 & 14.9 & 8.0 \\
+ Constant mortality & -1.23 & 10.9 & 34.1 & 27.1 & 13.8 & 8.0 \\
+ Constant taxes and transfers & -1.33 & 11.9 & 34.1 & 30.1 & 14.5 & 8.0 \\
+ Constant retirement age & -1.49 & 13.4 & 34.1 & 34.1 & 14.6 & 8.0 \\
+ No income risk & -1.47 & 13.2 & 33.9 & 33.9 & 13.8 & 8.0 \\
+ Annuities & -1.33 & 11.5 & 34.2 & 34.2 & 17.2 & 8.0 \\
\hline Alternative fiscal rules & & & & & & \\
$\quad$ Only lower expenditures & -1.29 & 11.0 & 34.1 & 32.6 & 17.9 & 8.0 \\
Only higher taxes & -0.88 & 6.7 & 34.1 & 19.4 & 14.6 & 8.0 \\
Only lower benefits & -1.50 & 12.9 & 34.1 & 39.1 & 18.4 & 8.0 \\
\hline
\end{tabular}

Notes: $\Delta r, \overline{\Delta \log \frac{W}{Y}}, \bar{\Delta}^{\text {comp }}$, and $\bar{\Delta}^{\text {soe }}$ denote the changes in the model simulation between 2016 and 2100, with $\Delta r$ reported in percentage points and the other three reported in percent $(100 \cdot \log )$.

government consumption reductions.

Changes in $r$ and $W / Y$. Table 4 reports the simulation results for $\Delta r$ and $\overline{\Delta \log W / Y}$, together with the corresponding average compositional effect $\bar{\Delta}^{\text {comp }}$, the average small open economy effect $\bar{\Delta}^{\text {soe }}$, and the average asset demand and supply semielasticities $\bar{\epsilon}^{d}$ and $\bar{\epsilon}^{s} \cdot{ }^{47}$ We present results from our preferred model specification on the second line, and reproduce results from the sufficient statistic analysis on the first line as a point of comparison.

Overall, the model results are close to the sufficient statistic analysis, with an identical $\Delta r=-1.23 p p$ in both the model and sufficient statistic analysis, and $\overline{\Delta \log W / Y}=10.3 \%$ in the model compared to $9.9 \%$ in the sufficient statistic analysis. The formulas $\Delta r=$ $-\frac{\bar{\Delta}^{s o e}}{\bar{\epsilon}^{d}+\bar{\epsilon}^{s}}$ and $\overline{\Delta \log W / Y}=\frac{\bar{\epsilon}^{s}}{\bar{\epsilon}^{d}+\bar{\epsilon}^{s}} \bar{\Delta}^{\text {soe }}$ from proposition 5 provide an excellent approximation to the full model results, predicting $\Delta r \approx-1.21 \mathrm{pp}$ and $\overline{\Delta \log W / Y} \approx 9.7 \%$. Given the success of the first-order approximation formulas, the close match between the model and the sufficient statistic results reflects three facts: a) the model calibration successfully approximates the average compositional effect $\bar{\Delta}^{\text {comp }}, \mathrm{b}$ ) the non-compositional effects of

\footnotetext{
${ }^{47}$ Here, $\bar{\Delta}^{\text {comp }}$ is calculated as in section 3 , and we construct $\bar{\Delta}^{\text {soe }}$ by simulating the model for each country given a fixed $r_{0}$. For each country, the semielasticities $\epsilon^{d, c}$ and $\epsilon^{s, c}$ are obtained by perturbing $r$ at a small open economy steady state constructed with 2100 demographics, and calculating the effect on steady-state $W / Y$ and $K / Y$.
} 
aging, $\bar{\Delta}^{\text {soe }}-\bar{\Delta}^{\text {comp }}$, are relatively small, and c) the model asset demand sensitivity $\bar{\epsilon}^{d}$ is relatively close to that implied by proposition $4 .{ }^{48}$

For a), the model calibration closely approximates the compositional effect because it fits the three inputs to $\Delta^{c o m p}$ in each country: we directly match the initial age profile of income, select parameters that approximate the age profile of wealth, and feed in the exact projected change in the age distribution.

To understand b) and c), we sequentially shut off the forces that distinguish the full model from the baseline model underlying the sufficient statistic result. We do this along six rows in table 4 . The first four leave the initial calibration intact but shut off dynamic changes: first holding constant bequests received, then perceived mortality, taxes and transfers, and retirement age. ${ }^{49}$ The last two involve changes to the steady-state calibration itself, first shutting off income risk, and then replacing bequests at death with annuities. By the final row, we have nearly recovered the baseline model, with the only difference being that our calibration is not flexible enough to perfectly hit $\bar{\Delta}^{\text {comp }}$.

The $\bar{\epsilon}^{d}$ in the full model is similar to that in the baseline model, reflecting two offsetting forces. Relative to the baseline model, the presence of bequests pushes $\bar{\epsilon}^{d}$ higher, since the savings response to $r$ can accumulate across generations (e.g. Barro 1974). The absence of annuities pushes $\bar{\epsilon}^{d}$ lower, since forcing individuals to self-insure against idiosyncratic mortality risk makes savings less sensitive to $r$. In table 4, after both forces are shut off by removing bequests and introducing annuities, $\bar{\epsilon}^{d}$ is on net almost unchanged.

The non-compositional effect of aging $\bar{\Delta}^{\text {soe }}-\bar{\Delta}^{\text {comp }}$ reflects three small, and partially offsetting, demographic forces. First, bequests push up $\bar{\Delta}^{\text {soe }}$ as the population is aging, since fewer heirs split each bequest; when bequests received are kept constant, $\bar{\Delta}^{\text {soe }}$ falls from $30.3 \%$ to $27.0 \%$. Second, higher taxes and lower social security benefits push down $\bar{\Delta}^{\text {soe }}$ on net. When these are held constant and the budget is balanced solely with expenditure cuts, $\bar{\Delta}^{\text {soe }}$ recovers from $27.1 \%$ to $30.1 \%$. Last, the delayed retirement age pushes down $\bar{\Delta}^{\text {soe }}$ by reducing savings and increasing labor supply; when the retirement age is kept constant, $\bar{\Delta}^{\text {soe }}$ rises from $30.1 \%$ to $34.1 \%$, and now agrees exactly with $\bar{\Delta}^{\text {comp }} .50$

\footnotetext{
${ }^{48}$ The $\bar{\epsilon}^{s}$ are identical across all settings since it is only a function of external parameters and moments that are targeted in the calibration.

${ }^{49}$ To make constant bequests received consistent with equilibrium, we assume that government taxes/augments bequests to keep them at the initial level. For mortality, we assume that the mortality rates perceived by individuals ex ante are held constant, while the population still evolves according to objective mortality rates that can change over time. For all these changes to the model, we assume that governments adjust $G_{t}$ to maintain a constant debt level.

${ }^{50}$ One potentially surprising feature of table 4 is that perceived mortality has little effect on asset accumulation. This is largely because bequest preferences and social security reduce the role of longevity as a savings motive; in appendix F, we show that Gagnon et al. (2021) find large effects from mortality reductions in a model where these features are absent.
} 
While robust to most features of the model, the close agreement of $\bar{\Delta}^{\text {soe }}$ and $\bar{\Delta}^{\text {comp }}$ does not hold when the fiscal shortfall is closed in a very one-sided way. If the entire shortfall is closed with higher taxes, less after-tax income is available for saving, and $\bar{\Delta}^{\text {soe }}$ declines to $19.4 \%$. If the entire shortfall is closed with benefit cuts, individuals must save more to fund their own retirement, and $\bar{\Delta}^{\text {soe }}$ rises to $39.1 \%$. In our main calibration, the shortfall is covered by an even mix of tax increases, benefit cuts, and spending cuts (which are neutral). The absence of a large effect reflects the offsetting effects of tax and benefit adjustments. ${ }^{51}$

Changes to net foreign asset positions. Appendix figure A.10 illustrates the model's predictions for the change in net foreign asset positions. Almost all changes in NFAs over time are explained by differences in $\Delta^{s o e}$, which are in turn mainly driven by differences in compositional effects $\Delta^{\text {comp }}$. However, compositional effects do not quite explain all the variation in NFAs: although non-compositional effects $\Delta^{\text {soe }}-\Delta^{\text {comp }}$ are small on average, they vary somewhat across countries.

Transition dynamics. We numerically solve for the transition dynamics in our extended model, and display the resulting paths of world $r$ and $W / Y$ in figure 8. To test the how well the long-run sufficient statistic formulas in propositions 2-3 work at different horizons, we apply them at each date $t$, combining the time-varying compositional effects $\bar{\Delta}_{t}^{\text {comp }}$ with the long-run elasticities $\bar{\epsilon}^{d}$ and $\bar{\epsilon}^{s}$. As we already know from table 4 , the two series nearly coincide by 2100 . Their dynamics are also quite similar, but the model predicts a somewhat faster decline in $r$ and rise in $W / Y$. Both phenomena reflect the fact that the long-run semielasticities $\bar{\epsilon}^{d}$ overstate the short-run response of asset accumulation to interest rates. For $r$, this implies that interest rates have to fall more in the short run to clear the asset market. For $W / Y$, this implies that asset supply is responsible for more of the adjustment, since the supply adjustment is instantaneous in our model.

Overall, this exercise highlights that calculating $\bar{\Delta}_{t}^{\text {comp }}$ at different points in time can be useful to predict general equilibrium transition dynamics, although getting the exact timing right requires a structural model.

\footnotetext{
${ }^{51}$ The importance of fiscal adjustment choices for macroeconomic outcomes has been discussed in the pension reform literature (see, for example, Feldstein 1974, Auerbach and Kotlikoff 1987, and Kitao 2014).
} 
A. Change in world $r$

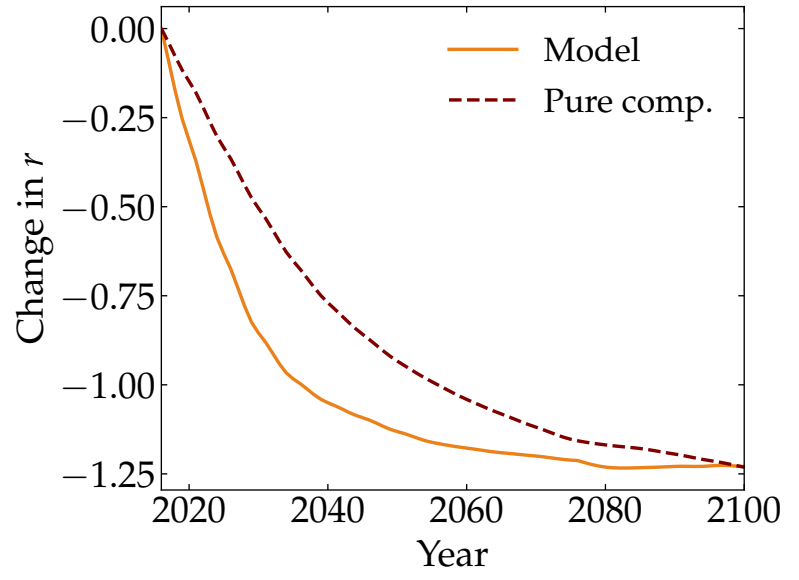

B. Change in world $W / Y$

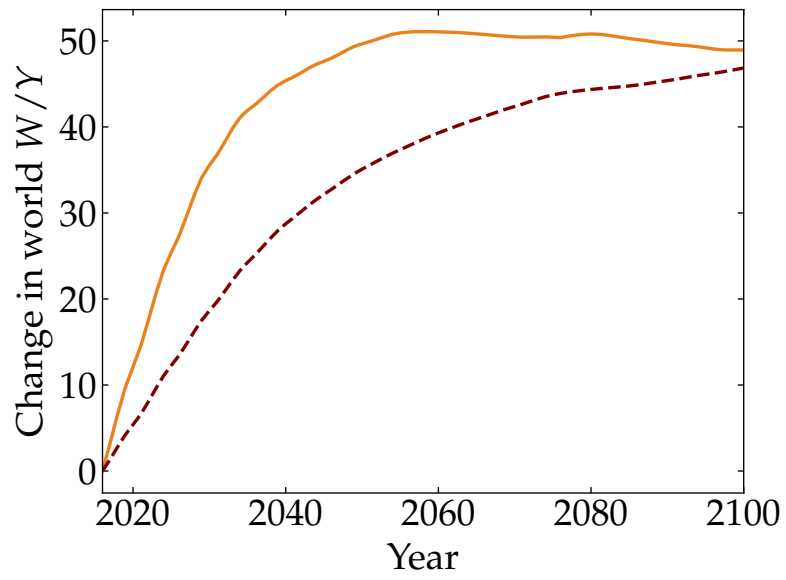

Figure 8: Transition dynamics for rates of return and wealth

Notes: This figure presents the model change in world interest rate and wealth-to-GDP between 2016 and 2100. Solid lines correspond to simulations from our preferred model specification, dashed lines to the sufficient statistic formulas $\Delta r=-\frac{\bar{\Delta}_{t}^{\text {comp }}}{\bar{\epsilon}^{d}+\bar{\epsilon}^{s}}$ and $\frac{W_{0}}{Y_{0}} \overline{\Delta \log W / Y}=\frac{W_{0}}{Y_{0}} \frac{\bar{\epsilon}^{s}}{\bar{\epsilon}^{d}+\bar{\epsilon}^{s}} \bar{s}_{t}^{\text {comp }} . r$ is in pp and $W / Y$ in percent.

\section{Demographic change and savings rates}

So far, we have analyzed demographics through the lens of stocks: wealth, capital, and net foreign asset positions. An alternative perspective is to focus on flows: savings, investment, and the current account.

The flow perspective has a long tradition in the literature on aging. ${ }^{52}$ One key observation in this literature is that the savings rate is hump-shaped in age, so that as the population continues to age, the aggregate savings rate eventually declines. Observers have made various macroeconomic predictions based on this effect: that aging will raise interest rates (Lane 2020), decrease standards of living by impairing capital accumulation (Bloom, Canning and Fink 2010), or exert inflationary pressure as the number of consumers increases relative to the number of producers (Goodhart and Pradhan 2020).

These predictions are not borne out in our analysis. Instead, we find that aging unambiguously lowers the real interest rate, thereby increasing capital intensity and output. ${ }^{53}$ A lower real interest rate also implies less inflationary pressure in any standard model in which this pressure is captured by the natural interest rate. ${ }^{54}$

\footnotetext{
${ }^{52}$ See, e.g., Summers and Carroll (1987), Auerbach and Kotlikoff (1990), Bosworth et al. (1991), Higgins (1998), and Lane (2020).

${ }^{53}$ GDP per person may still decline overall if the workforce composition effect overwhelms capital deepening, but this is a separate channel that does not go through savings, as is clear from equation (8).

${ }^{54}$ That is, in a version of our model with nominal rigidities, if monetary policy does not fully accommodate the natural rate decline by lowering the intercept of its Taylor rule, actual inflation will decline.
} 


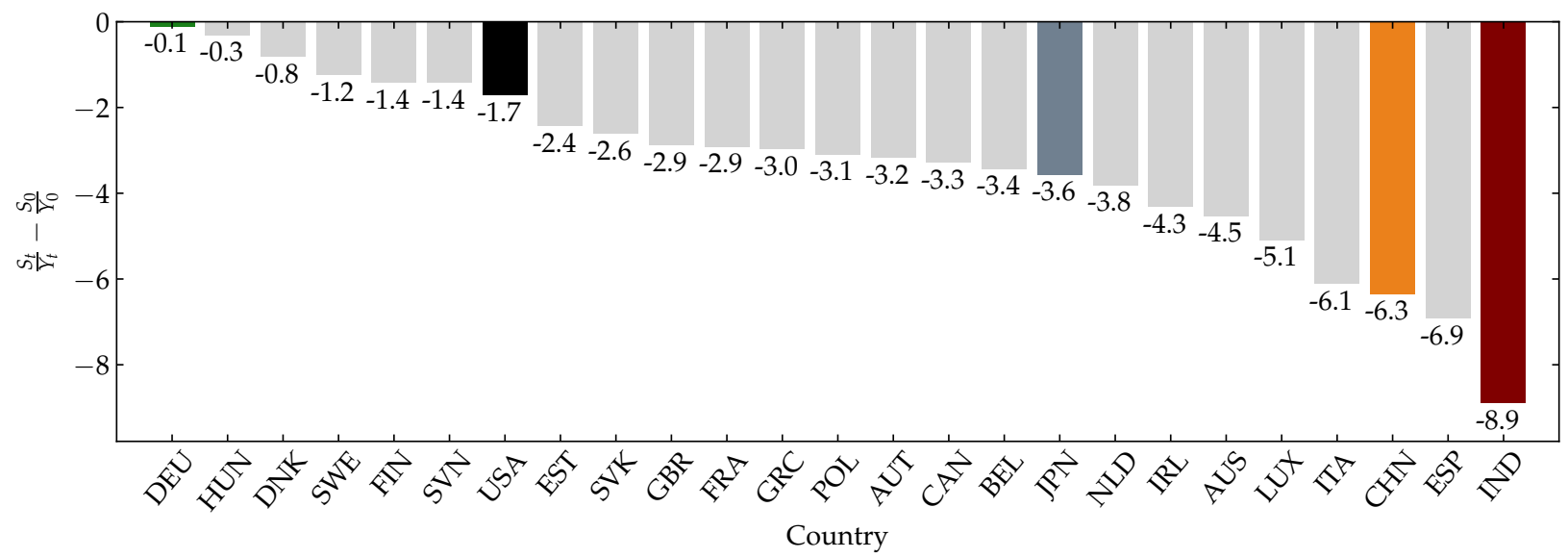

Figure 9: Compositional effects and savings

Notes: Each bar shows the value of the predicted change in the savings-to-GDP ratio from the compositional effect between 2016 and 2100 across countries, reported in pp. Appendix E details the calculation.

To unpack this apparent contradiction, we return to our baseline model of section 2 . We first show that this model also predicts a negative effect of aging on savings rates going forward, in line with the literature discussed above. To do this, we note that the aggregate net private savings rate in a small open economy satisfies

$$
\frac{S_{t}}{Y_{t}} \propto \frac{\sum_{j} \pi_{j t} S_{j 0}}{\sum_{j} \pi_{j t} h_{j 0}},
$$

where $s_{j 0}$ is average net personal savings by age at date 0 (see appendix $\mathrm{E}$ for a proof). Equation (28) shows that holding $r$ constant, changes in the aggregate savings rate are purely determined by compositional forces, just like with wealth-to-GDP. We can therefore also measure this effect using a shift-share calculation..$^{55}$ Figure 9 shows the resulting projected savings rates until 2100. These are indeed negative in all countries. ${ }^{56}$

In panel A of figure 10, which represents steady-state equilibrium between savings and investment, we depict this effect as a leftward shift in the private savings curve. At first glance, this might seem to imply an increase in $r$, as represented by the hollow circle. But since demographic change lowers the population growth rate and therefore $g$, the other curve-representing net investment and public borrowing—also shifts left, and the

\footnotetext{
${ }^{55}$ While we could in principle perform this calculation using using measured savings rates by age, we prefer instead to express (28) using cross-sectional profiles of assets and income alone. This avoids the amplification of measurement error that stems from taking the difference between two large quantities, disposable income and consumption, that are themselves observed with error.

${ }^{56}$ Figure A.11 shows, however, that in many countries, the effect was positive prior to 2016. This gives some support to the common view that aging of baby boomers has pushed up savings in recent decades.
} 
A. World equilibrium: flows

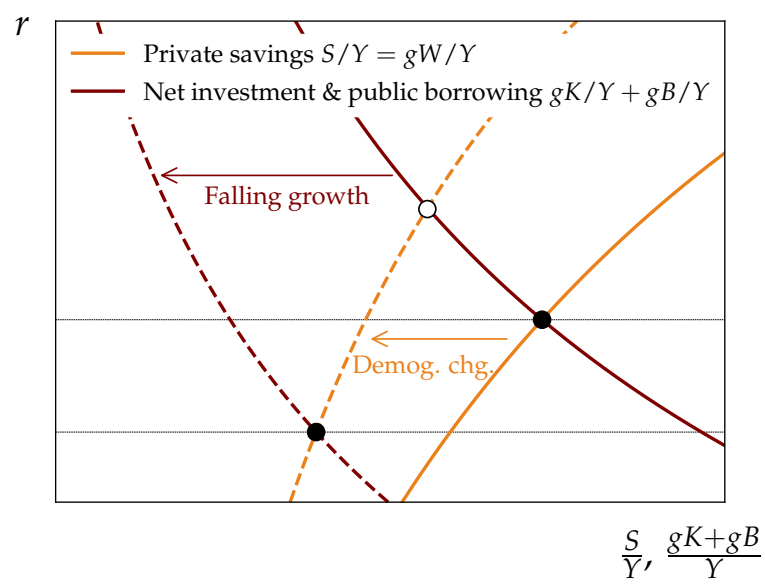

B. World equilibrium: stocks

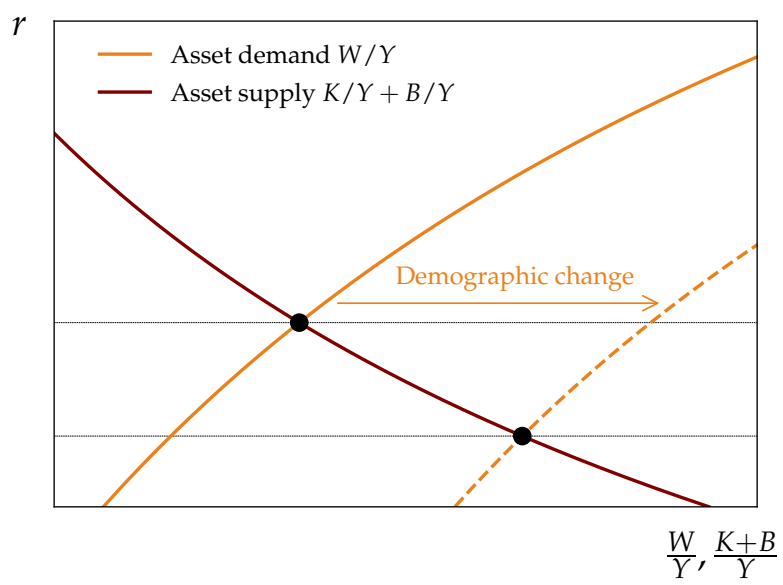

Figure 10: World asset market equilibrium

Notes: This figure represents asset market equilibrium in flow space (panel A) and in stock space (panel B). The growth rate $g$ converts Panel B into Panel A. At given $r$, demographics increases $W / Y$ and lowers $g$.

overall effect is a decline in $r$.

To understand this result, it is useful to compare to panel B, which depicts steadystate equilibrium between asset demand and supply. Here, only the asset demand curve shifts— to the right—and the unambiguous implication is a decline in $r .{ }^{57}$ But the curves in panel A are identical to panel B, just both multiplied by $g .{ }^{58}$ Hence, although both curves in panel A shift left, the net investment curve shifts left by more, producing the same decline in $r$ as in panel B. ${ }^{59}$

We conclude that the "flow" view of equilibrium in panel A is in principle just as valid as the "stock" view of equilibrium in panel B, but only if we remember the effect of $g$ on net investment. Ignoring this effect in the context of demographic change, which can significantly push down long-run $g$, may give the wrong sign for the change in $r$.

\footnotetext{
${ }^{57}$ For given $r$, standard neoclassical theory implies that $K / Y$ is not affected by demographic change. In our model, $B / Y$ is also constant. This is subject to debate, but we note that the effect of demographic change on $B / Y$ could take either sign: if lawmakers hold deficits $g B / Y$ constant, $B / Y$ will rise, but if they hold net payments $(r-g) B / Y$ constant, it will fall.

${ }^{58}$ Net savings-to-GDP is $S_{t} / Y_{t}=\left(W_{t+1}-W_{t}\right) / Y_{t}$. In steady state, this is $S / Y=g(W / Y)$, since $W_{t+1}=$ $(1+g) W_{t}$. Similarly, net investment-to-GDP is $g(K / Y)$ and net public borrowing-to-GDP is $g(B / Y)$.

${ }^{59}$ Goodhart and Pradhan (2020) acknowledge that investment can also fall in response to demographics, but argue that savings will fall faster than investment. An important part of their argument is that the labor scarcity caused by aging will trigger a rise in labor-saving investment demand. In our model, the capitallabor ratio does increase in equilibrium, but only because the real interest rate falls. See Moll et al. (2021) for a model in which automation leads to rising real interest rates.
} 


\section{Conclusion}

We project out the compositional effect of aging on the wealth-to-GDP ratio of 25 countries until the end of the twenty-first century. This effect is positive, large and heterogeneous across countries. According to our model, this will lead to capital deepening everywhere, falling real interest rates, and rising net foreign asset positions in India and China financed by declining asset positions in the United States.

\section{References}

Abel, Andrew B., "Will Bequests Attenuate the Predicted Meltdown in Stock Prices When Baby Boomers Retire?," Review of Economics and Statistics, November 2001, 83 (4), 589-595.

- , "The Effects of a Baby Boom on Stock Prices and Capital Accumulation in the Presence of Social Security," Econometrica, March 2003, 71 (2), 551-578.

Acemoglu, Daron and Pascual Restrepo, "Secular Stagnation? The Effect of Aging on Economic Growth in the Age of Automation," American Economic Review Papers and Proceedings, May 2017, 107 (5), 174-179.

Achdou, Yves, Jiequn Han, Jean-Michel Lasry, Pierre-Louis Lions, and Benjamin Moll, "Income and Wealth Distribution in Macroeconomics: A Continuous-Time Approach," Review of Economic Studies, April 2021.

Aguiar, Mark A., Manuel Amador, and Cristina Arellano, "Micro Risks and Pareto Improving Policies with Low Interest Rates," Working Paper 28996, National Bureau of Economic Research, July 2021.

Alvaredo, Facundo, Bertrand Garbinti, and Thomas Piketty, "On the Share of Inheritance in Aggregate Wealth: Europe and the USA, 1900-2010," Economica, April 2017, 84 (334), 239-260.

Ameriks, John and Stephen P. Zeldes, "How Do Household Portfolio Shares Vary with Age?," Manuscript, 2004.

Atkeson, Andrew, Jonathan Heathcote, and Fabrizio Perri, "The End of Privilege: A Reexamination of the Net Foreign Asset Position of the United States," Manuscript, July 2021.

Auclert, Adrien and Matthew Rognlie, "Inequality and Aggregate Demand," Working Paper 24280, National Bureau of Economic Research, February 2018.

_ , Bence Bardóczy, Matthew Rognlie, and Ludwig Straub, “Using the Sequence-Space Jacobian to Solve and Estimate Heterogeneous-Agent Models," Econometrica, 2021, Forthcoming.

Auerbach, Alan J. and Laurence J. Kotlikoff, Dynamic Fiscal Policy, Cambridge: Cambridge University Press, April 1987.

_ and _ , "Demographics, Fiscal Policy, and U.S. Saving in the 1980s and Beyond," Tax Policy and the Economy, 1990, 4, 73-101. 
Backus, David, Thomas Cooley, and Espen Henriksen, "Demography and Low-Frequency Capital Flows," Journal of International Economics, April 2014, 92, S94-S102.

Bárány, Zsofia, Nicholas Coeurdacier, and Stéphane Guibaud, "Capital Flows in an Aging World," Manuscript, July 2019.

Barro, Robert J., "Are Government Bonds Net Wealth?," Journal of Political Economy, November $1974,82(6), 1095-1117$.

Bloom, David E., David Canning, and Günther Fink, "Implications of Population Ageing for Economic Growth," Oxford Review of Economic Policy, December 2010, 26 (4), 583-612.

_, _, and Jaypee Sevilla, The Demographic Dividend: A New Perspective on the Economic Consequences of Population Change, RAND Corporation, February 2003.

Bornstein, Gideon, "Entry and Profits in an Aging Economy: The Role of Consumer Inertia," Manuscript, February 2020.

Börsch-Supan, Axel, Alexander Ludwig, and Joachim Winter, "Ageing, Pension Reform and Capital Flows: A Multi-Country Simulation Model," Economica, June 2006, 73 (292), 625-658.

Bosworth, Barry, Gary Burtless, and John Sabelhaus, "The Decline in Saving: Evidence from Household Surveys," Brookings Papers on Economic Activity, 1991, 1991 (1), 183-256.

Brülhart, Marius, Jonathan Gruber, Matthias Krapf, and Kurt Schmidheiny, "Behavioral Responses to Wealth Taxes: Evidence from Switzerland," American Economic Journal: Economic Policy, February 2021, forthcoming.

Cagetti, Marco, "Interest Elasticity in a Life-Cycle Model with Precautionary Savings," American Economic Review Papers and Proceedings, May 2001, 91 (2), 418-421.

Carroll, Christopher D., "The Method of Endogenous Gridpoints for Solving Dynamic Stochastic Optimization Problems," Economics Letters, 2006, 91 (3), 312-320.

Carvalho, Carlos, Andrea Ferrero, and Fernanda Nechio, "Demographics and Real Interest Rates: Inspecting the Mechanism," European Economic Review, September 2016, 88, 208-226.

Catherine, Sylvain, Max Miller, and Natasha Sarin, "Social Security and Trends in Wealth Inequality," SSRN Working Paper No 3546668, Social Science Research Network, Rochester, NY, February 2020.

Coppola, Antonio, Matteo Maggiori, Brent Neiman, and Jesse Schreger, "Redrawing the Map of Global Capital Flows: The Role of Cross-Border Financing and Tax Havens," Quarterly Journal of Economics, August 2021, 136 (3), 1499-1556.

Cutler, David M., James M. Poterba, Louise M. Sheiner, Lawrence H. Summers, and George A. Akerlof, "An Aging Society: Opportunity or Challenge?," Brookings Papers on Economic Activity, 1990, 1990 (1), 1-73.

Deaton, Angus, The Analysis of Household Surveys a Microeconometric Approach to Development Policy, Baltimore, MD: Johns Hopkins University Press, 1997. 
Domeij, David and Martin Flodén, "Population Aging and International Capital Flows," International Economic Review, July 2006, 47 (3), 1013-1032.

Eggertsson, Gauti B., Jacob A. Robbins, and Ella Getz Wold, "Kaldor and Piketty's Facts: The Rise of Monopoly Power in the United States," Working Paper 24287, National Bureau of Economic Research, February 2018.

_, Neil R. Mehrotra, and Jacob A. Robbins, "A Model of Secular Stagnation: Theory and Quantitative Evaluation," American Economic Journal: Macroeconomics, January 2019, 11 (1), 1-48.

Evans, Owen J., "Tax Policy, the Interest Elasticity of Saving, and Capital Accumulation: Numerical Analysis of Theoretical Models," American Economic Review, June 1983, 73 (3), 398-410.

Farhi, Emmanuel and François Gourio, "Accounting for Macro-Finance Trends: Market Power, Intangibles, and Risk Premia," Brookings Papers on Economic Activity, November 2018, 2018 (Fall).

Feldstein, Martin, "Social Security, Induced Retirement, and Aggregate Capital Accumulation," Journal of Political Economy, September 1974, 82 (5), 905-926.

_ , "The Welfare Cost of Capital Income Taxation," Journal of Political Economy, April 1978, 86 (2), S29-S51.

Gagnon, Etienne, Benjamin K. Johannsen, and David López-Salido, "Understanding the New Normal: The Role of Demographics," IMF Economic Review, March 2021.

Geanakoplos, John, Michael Magill, and Martine Quinzii, "Demography and the Long-Run Predictability of the Stock Market," Brookings Papers on Economic Activity, 2004, 2004 (1), 241307.

Gomme, Paul, B. Ravikumar, and Peter Rupert, "The Return to Capital and the Business Cycle," Review of Economic Dynamics, April 2011, 14 (2), 262-278.

Goodhart, Charles and Manoj Pradhan, The Great Demographic Reversal: Ageing Societies, Waning Inequality, and an Inflation Revival, 1st ed., Cham, Switzerland: Palgrave Macmillan, August 2020.

Gourinchas, Pierre-Olivier and Hélène Rey, "International Financial Adjustment," Journal of Political Economy, August 2007, 115 (4), 665-703.

Hall, Robert E., "Technical Change and Capital from the Point of View of the Dual," Review of Economic Studies, 1968, 35 (1), 35-46.

Havránek, Tomáš, “Measuring Intertemporal Substitution: The Importance of Method Choices and Selective Reporting," Journal of the European Economic Association, December 2015, 13 (6), 1180-1204.

Henriksen, Espen R., "A Demographic Explanation of U.S. and Japanese Current Account Behavior," Manuscript, December 2002.

Higgins, Matthew, “Demography, National Savings, and International Capital Flows," International Economic Review, 1998, 39 (2), 343-369. 
Hurd, Michael and James P. Smith, "Expected Bequests and Their Distribution," Working Paper 9142, National Bureau of Economic Research, September 2002.

İmrohoroğlu, Ayşe, Selahattin İmrohoroğlu, and Douglas H. Joines, "A Life Cycle Analysis of Social Security," Economic Theory, February 1995, 6 (1), 83-114.

Jakobsen, Katrine, Kristian Jakobsen, Henrik Kleven, and Gabriel Zucman, "Wealth Taxation and Wealth Accumulation: Theory and Evidence From Denmark," Quarterly Journal of Economics, February 2020, 135 (1), 329-388.

Jones, Callum, "Aging, Secular Stagnation and the Business Cycle," Manuscript, January 2020.

Karabarbounis, Loukas and Brent Neiman, “The Global Decline of the Labor Share," Quarterly Journal of Economics, February 2014, 129 (1), 61-103.

Kitao, Sagiri, "Sustainable Social Security: Four Options," Review of Economic Dynamics, October 2014, 17 (4), 756-779.

Kleven, Henrik and Esben Schultz, "Estimating Taxable Income Responses Using Danish Tax Reforms," American Economic Journal: Economic Policy, November 2014, 6 (4), 271-301.

Kopecky, Joseph and Alan M. Taylor, "The Murder-Suicide of the Rentier: Population Aging and the Risk Premium," Working Paper 26943, National Bureau of Economic Research, April 2020.

Kotlikoff, Laurence J., Kent Smetters, and Jan Walliser, "Privatizing Social Security in the United States-Comparing the Options," Review of Economic Dynamics, July 1999, 2 (3), 532-574.

Krueger, Dirk and Alexander Ludwig, "On the Consequences of Demographic Change for Rates of Returns to Capital, and the Distribution of Wealth and Welfare," Journal of Monetary Economics, January 2007, 54 (1), 49-87.

Krusell, Per and Anthony A. Smith, "Is Piketty's "Second Law of Capitalism" Fundamental?," Journal of Political Economy, August 2015, 123 (4), 725-748.

Kuhn, Moritz, Moritz Schularick, and Ulrike I. Steins, "Income and Wealth Inequality in America, 1949-2016," Journal of Political Economy, March 2020, 128 (9), 3469-3519.

Lane, Phillip, "International Inflation Co-Movements," Speech at the Inflation: Drivers and Dynamics 2020 Online Conference, May 2020, Federal Reserve Bank of Cleveland/European Central Bank.

- and Gian Maria Milesi-Ferretti, "International Financial Integration in the Aftermath of the Global Financial Crisis," IMF Working Paper no 17/115, May 2017.

Lee, Ronald D., "Population Age Structure, Intergenerational Transfer, and Wealth: A New Approach, with Applications to the United States," The Journal of Human Resources, 1994, 29 (4), 1027-1063.

Lisack, Noëmie, Rana Sajedi, and Gregory Thwaites, "Demographic Trends and the Real Interest Rate," Manuscript, December 2017.

Maestas, Nicole, Kathleen J. Mullen, and David Powell, "The Effect of Population Aging on Economic Growth, the Labor Force and Productivity," Working Paper 22452, National Bureau of Economic Research, July 2016. 
Mankiw, N. Gregory and David N. Weil, "The Baby Boom, the Baby Bust, and the Housing Market," Regional Science and Urban Economics, May 1989, 19 (2), 235-258.

Moll, Benjamin, Lukasz Rachel, and Pascual Restrepo, "Uneven Growth: Automation's Impact on Income and Wealth Inequality," Working Paper 28440, National Bureau of Economic Research, February 2021.

Nardi, Mariacristina De, "Wealth Inequality and Intergenerational Links," Review of Economic Studies, 2004, 71 (3), 743-768.

_ , Eric French, and John B. Jones, "Why Do the Elderly Save? The Role of Medical Expenses," Journal of Political Economy, February 2010, 118 (1), 39-75.

_ , _ , John Bailey Jones, and Rory McGee, "Why Do Couples and Singles Save During Retirement?," Working Paper 28828, National Bureau of Economic Research, May 2021.

_, Selahattin Imrohoroğlu, and Thomas J. Sargent, "Saving and Pension Reform in General Equilibrium Models," Oxford Review of Economic Policy, March 2001, 17 (1), 20-39.

Oberfield, Ezra and Devesh Raval, "Micro Data and Macro Technology," Econometrica, 2021, 89 (2), 703-732.

Papetti, Andrea, "Demographics and the Natural Real Interest Rate: Historical and Projected Paths for the Euro Area," SSRN Working Paper No 3363512, March 2019.

Penn Wharton Budget Model, "Penn Wharton Budget Model: Dynamic OLG Model," Technical Report, May 2019.

Peters, Michael and Conor Walsh, "Declining Dynamism, Increasing Markups and Missing Growth: The Role of the Labor Force," Manuscript, November 2019.

Piketty, Thomas and Gabriel Zucman, "Capital is Back: Wealth-Income Ratios in Rich Countries 1700-2010," Quarterly Journal of Economics, August 2014, 129 (3), 1255-1310.

Poterba, James M., “Demographic Structure and Asset Returns," Review of Economics and Statistics, November 2001, 83 (4), 565-584.

Rachel, Lukasz and Lawrence H. Summers, "On Secular Stagnation in the Industrialized World," Brookings Papers on Economic Activity, 2019, pp. 1-54.

- and Thomas Smith, "Secular Drivers of the Global Real Interest Rate," Bank of England Staff Working Paper No. 571, December 2015.

Sabelhaus, John and Alice Henriques Volz, "Are Disappearing Employer Pensions Contributing to Rising Wealth Inequality?," FEDS Notes No 2019-02-01, February 2019.

_ and _ , "Social Security Wealth, Inequality, and Lifecycle Saving," Working Paper 27110, National Bureau of Economic Research, May 2020.

Saez, Emmanuel and Stefanie Stantcheva, "A Simpler Theory of Optimal Capital Taxation," Journal of Public Economics, June 2018, 162, 120-142. 
Solow, Robert M., "A Contribution to the Theory of Economic Growth," Quarterly Journal of Economics, February 1956, 70 (1), 65-94.

Straub, Ludwig, "Consumption, Savings, and the Distribution of Permanent Income," Manuscript, June 2019.

Summers, Lawrence H., "Capital Taxation and Accumulation in a Life Cycle Growth Model," American Economic Review, September 1981, 71 (4), 533-544.

- and Christopher D. Carroll, "Why is U.S. National Saving so Low?," Brookings Papers on Economic Activity, 1987, 1987 (2), 607-642.

Willis, Robert J., "Life Cycles, Institutions, and Population Growth: A Theory of the Equilibrium Interest Rate in an Overlapping Generations Model," in W. Brian Arthur and Gerry Rodgers, eds., Economics of changing age distributions in Developed Countries, Oxford University Press, 1988, pp. 106-138.

Young, Eric R., "Solving the Incomplete Markets Model with Aggregate Uncertainty Using the Krusell-Smith Algorithm and Non-Stochastic Simulations," Journal of Economic Dynamics and Control, January 2010, 34 (1), 36-41.

Zoutman, Floris T., "The Elasticity of Taxable Wealth: Evidence from the Netherlands," Manuscript, November 2018.

Zucman, Gabriel, "The Missing Wealth of Nations: Are Europe and the U.S. net Debtors or net Creditors?," Quarterly Journal of Economics, April 2013. 